Purdue University

Purdue e-Pubs

Purdue CIBER Working Papers

Krannert Graduate School of Management

$1-1-2000$

\title{
Information and Inventory Recourse for a Two- Market, Price-Setting Retailer
}

Maqbool Dada

Purdue University

Nicholas C. Petruzzi

University of Illinois

Follow this and additional works at: http:// docs.lib.purdue.edu/ciberwp

Dada, Maqbool and Petruzzi, Nicholas C., "Information and Inventory Recourse for a Two-Market, Price-Setting Retailer " (2000).

Purdue CIBER Working Papers. Paper 10.

http://docs.lib.purdue.edu/ciberwp/10

This document has been made available through Purdue e-Pubs, a service of the Purdue University Libraries. Please contact epubs@purdue.edu for additional information. 


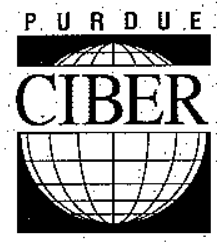

Center for International

Business Education and Research

\title{
Information and Inventory Recourse for a Two-Market, Price-Setting Retailer
}

\author{
Maqbool Dada \\ Purdue University \\ Nicholas Petruzzi \\ University of Illinois
}

2000-010

Krannert Graduate School of Management

Purdue University

1310 Krannert Building

West Lafayette, IN 47907-1310

(765) $494-4463$

Fax (765) 494-9658 


\title{
INFORMATION AND INVENTORY ReCOURSE FOR A Two-MARKeT, PRICE-SETTING RETAIER
}

\author{
NICHOLAS C. PETRUZZI* \\ (* contact author) \\ Department of Business Administration \\ University of Illinois \\ 350 Commerce West Building \\ 1206 South Sixth Street \\ Champaign, IL 61820 \\ phone: $217-333-9578$ \\ fax: $217-244-7969$ \\ email: petruzzi@uiuc.edu \\ MAQBOOL DADA \\ Krannert Graduate School of Management \\ Purdue University \\ West Lafayette, IN 47907-1310 \\ phone: $765-494-4490$ \\ fax: 765-496-1778 \\ email: dada@mgmt.purdue.edu
}

OCTOBER 1999

Revised: JUUNE 2000

\begin{abstract}
We analyze the problem of determining inventory and pricing decisions in a two-period retail setting when an opportunity to refine information about uncertain demand is available. The model extends the newsvendor problem with pricing by allowing for multiple suppliers, the pooling of procurement resources, and more general informational dynamics. One contribution is the solution procedure: we show that all decisions (up to seven in all, including recourse decisions) can be determined uniquely as a function of a surrogate first-period decision called the stocking factor. Hence, the two-period decision problem with recourse reduces to a search for one decision variable. A second contribution is the policy implications: we find that the cost of learning is (1) a consequence of censored information because, on the margin, learning is free if full information is guaranteed; (2) measured in the form of an increased stocking factor; and (3) shared with the consumer in the form of a higher selling price when demand uncertainty is additive. A third contribution is the application of the results to three motivating examples: A market research problem in which a product is introduced in a test market prior to a widespread launch; a global newsvendor problem in which a seasonal product is sold in two different countries with non-overlapping selling seasons; and a minimum-quantity commitment problem in which procurement resources for multiple purchases may be pooled.
\end{abstract}


In October 1999, The New York Times reported that Coca-Cola Co. was conducting a field test to adjust prices dynamically based on anticipated demand patterns and stock availability (Hays, 1999). Then, in May 2000, Coca-Cola Co. issued a press release announcing their intention to invest $\$ 100$ million to link more than a half-million vending machines worldwide through intelligent vending technology. According to the press release, "Intelligent vending is expected to substantially improve inventory management, and deliver superb service to customers and a quality purchase experience to consumers." In time, Coca-Cola Co. expects to provide cashless vending, coupons, and Internet browsing.

Coca-Cola's initiatives into intelligent vending underscore the observation that information about one retail market can improve operating efficacy in related markets. A natural consequence of this dependency is that a goal in the first market is to invest in learning by controlling inventory and pricing decisions, even if such a goal comes at the expense of not maximizing local profits. The intuition is that learning can lead to improvements in future markets that ultimately produce higher system-wide profits.

The following three illustrations further highlight the natural role that information gathered in one market can play to enhance decision making in a related market separated in time, in space, or in both. The first example is reminiscent of the recent market test by Frito-Lay, Inc. of WOW! ${ }^{\mathrm{TM}}$, its line of snacks made with its fat-free cooking oil, Olean, before a national launch (Frito-Lay, Inc., 1997). It also is similar to market tests conducted regularly by retailers (Lilien et al., 1992). The second example is a generalization of a recent two-period model by Kouvelis and Gutierrez (1997). And the third example is an extension of a multi-period decision problem due to Bassok and Anupindi (1997).

\section{Example 1. Test Market}

A firm introduces a new product in a test market prior to a widespread launch. Before the start of the test, the firm's decisions include: (1) how much stock to supply for the test market and (2) what selling price to set in the test market. Then, after observing sales in the test market, the firm can: (3) refine its estimate of the potential market size of the overall market, (4) determine how much stock to supply for the overall market, and (5) reassess its pricing policy for the overall market. 


\section{Example 2. Global Newsvendor}

A firm sells a seasonal product with uncertain demand in two countries with nonoverlapping selling seasons. Before the start of the first selling season, the firm's decisions include: (1) how much stock to supply to the first country's market, (2) how much stock to commit to the second country's market, and (3) what selling price to set in the first country's market. Then, after observing sales in the first country's market, the firm can: (4) refine its estimate of the potential market size of the second country's market, (5) determine how much of any unsold inventory from the first country's market to transship to the second country's market, (6) decide how much stock to procure from a premium-priced supplier for the second country's market, and (7) set a selling price for the second country's market. Note that revenue generated in the second country's market will be subject to exchange rate risk.

\section{Example 3. Supply Contracts with Minimum Quantity Commitment}

A firm commits to a long-term contract specifying a minimum total quantity amount that will be purchased over the course of a multi-period selling season. Before the start of the first period, the firm's decisions include: (1) how much stock to commit to each period of the selling season and (2) the selling price of the product. Then, at the end of each period, after observing sales, the firm can: (3) refine its estimate of the potential market size for the upcoming period, (4) determine how much stock to procure at a premium price to supplement its available stock, and (5) adjust its selling price.

The goal of this paper is to develop a modeling framework that captures the essential features of these three examples and to use that framework to answer a variety of questions that arise naturally. For example: How can optimal pricing and inventory decisions be determined when recourse is available? Should price be increased today because there is an opportunity to learn about tomorrow's market? Likewise, should inventory investment be increased? To that end, we define a two-period extension to the newsvendor problem with pricing by allowing for multiple suppliers and more general informational dynamics. The framework is defined by the following sequence of events and decisions:

Step (1a): Before the beginning of period 1, determine how much to buy from a supplier for delivery in period 1 and in period 2 , respectively. This is equivalent to making a commitment to purchase a specific amount over the life of a 2-period contract.

Step (1b): Also before the beginning of period 1, determine the price at which to sell the product. This implies that the firm can affect market demand through its retail selling price. Demand uncertainty is introduced in an additive manner, which means that price influences expected demand, but not demand variance. We assume that price and demand are inversely related so 
that increases in price correspond to decreases in demand. Thus, for a given level of stocking quantity, an increase in price results in a lower likelihood of stock-outs.

Step (2): Observe the sales in period 1 and then exploit that information by refining the characterization of the demand uncertainty prescribed for the second period. We assume unobservable lost sales: If there is inventory left over from period 1, then sales corresponds to demand, which implies that full information is available to update demand uncertainty in period 2. But, if there is no inventory left over from period 1, then sales provides censored information regarding demand, which implies that incomplete information is available to update demand uncertainty in period 2. Raising the stocking quantity, the selling price, or both in period 1 increases the likelihood of obtaining full information.

Step (3): Given the refined estimate for demand in period 2, determine the stocking quantity and selling price for period 2 . Note that the stocking quantity decision was made tentatively at the beginning of period 1 (Step 1a). However three alternatives for recourse exist at the beginning of period 2: a portion of the original procurement quantity can be discarded rather than stocked for retail sale, some or all of any inventory left over from period 1 can be held for (or transferred to) period 2, and supplemental stock can be purchased at a premium price. Note also that if the second market is foreign, then the unit revenue in terms of the home currency is uncertain because of exchange rate fluctuations.

The timing of these events naturally leads to the formulation of the decision problem as a two-stage stochastic program with recourse (where each time period of our model constitutes a "stage"). In our model, Steps $1 \mathrm{a}$ and $1 \mathrm{~b}$ correspond to the first stage, Step 3 corresponds to the second stage, and Step 2 provides information that links the two stages. Our model makes a contribution to the literature in several ways. First, we extend the newsvendor problem with pricing by incorporating more general informational dynamics and, in effect, multiple suppliers. Second, we incorporate retail pricing and informational dynamics into the global newsvendor problem of Kouvelis and Gutierrez (1997) and into the minimum quantity commitment model of Bassok and Anupindi (1997). Finally, by incorporating aspects of marketing, economics, and finance, we show how an interdisciplinary approach to traditional operations management problems can improve the quality of decision-making.

The remainder of this paper is organized as follows. Section 1 positions this paper in relation to the existing literature. Then, in Section 2, we develop the formal mathematical model. In analyzing the 
model, we follow a standard approach of working backwards: First we solve the recourse problem as though all relevant input parameters have already been updated based on the first period's decisions and observations (Section 3); then we identify mechanisms for using information obtained from the first period to update the input parameters used in the recourse problem (Section 4); and finally, exploiting the foresight of how parameters will be updated and the recourse problem solved based on the events of period 1, we solve the first-stage decision problem and examine the benefits of linking related markets together rather than treating them as being independent (Section 5). The results of our analysis will show that this complex problem with up to seven decision variables reduces to a search for one decision: the optimal stocking factor (which we define in Section 2) for the first period. Moreover, our results will indicate that much of the insight regarding the impact that transferring information and inventory between retail markets has on operational decision making can be explained within the context of the optimal stocking factor. We discuss the applicability and scope of our results in Section 6 .

\section{RELATIONSHIP TO THE LITERATURE}

The model developed in this paper spans several streams of literature. One such stream is the literature on the price-setting newsvendor problem. Petruzzi and Dada (1999a) provide an integrative review of this problem; however it can be described succinctly as follows: given economic parameters and a distribution function to characterize demand, a stocking quantity and a selling price must be determined before the price-dependent, uncertain demand for a single period is realized. Although this construct is fundamental to our recourse problem, the analysis developed here is more general. In effect, the recourse problem analyzed in this paper can be thought of as a multiple-supplier, price-setting newsvendor problem because the stocking quantity made available for the second stage of our two-stage problem originates from as many as three available sources: the amount of stock committed to prior to the beginning of the first period represents the first source; the random amount of stock left over from the first period represents the second source; and the amount that can be ordered at a price premium represents the third source. 
From the perspective of a manager about to make the recourse decisions, the per-unit "purchase" cost associated with the first source is zero because the investment in this stock is sunk, committed to a period earlier. However, the supply of this stock is constrained, limited to the decision made a period earlier. In addition, to this manager, the per-unit purchase cost associated with the second source is the cost of transshipping a unit of stock from market 1 to market 2, if applicable. The supply of this stock also is limited, constrained by the realized value of the random number of leftovers resulting from the first period's operations. We assume that the supply of stock available at a price premium is unlimited; however, presumably, the per-unit purchase cost associated with it is strictly greater than the corresponding cost of either of the other two supply sources.

A second stream of literature is that on dynamic inventory models with pricing and stochastic demand. As in Ernst (1970), Zabel (1972), Alpern and Snower (1988), Thowsen (1975), and Petruzzi and Dada (1999b), leftover inventory is available for sale in subsequent periods, but demand in excess of supply is lost. However, the informational dynamics in our two-period model are more general. We explicitly incorporate mechanisms for refining the characterization of demand uncertainty based on the observation of previous sales. Neither Ernst, Zabel, nor Thowsen incorporate updating procedures in his model; and, Alpern and Snower and Petruzzi and Dada each investigate a variant of a more specific case in which the possibility exists to resolve uncertainty completely.

A third stream of literature is that on stochastic inventory theory with unobservable lost sales. Recall, step 2 in our model calls for the refinement of the second-period demand distribution based on the observation of first-period sales. This modeling specification leads to censored information because, generally speaking, the number of sales in any given period cannot exceed the smaller of demand and supply for the period. As a result, the observation of sales in a stock-out situation provides only a lower bound for the actual demand that occurs. To avoid censored demand information, both sales and shortages must be recorded; but, in many cases, the observation and recording of each occurrence of unfilled demand simply is not practical. 
Relevant papers appearing either in the operations management or the economics literature address only aspects of the learning model employed in this paper. In particular, Lariviere and Porteus (1999); Krouse and Senchack (1977); Harpaz et al. (1982); Braden and Freimer (1991); Nahmias (1993); and Agrawal and Smith (1996) incorporate the idea of learning from censored information into inventory models, but they assume that the selling price is given rather than incorporate it as a decision variable. On the other hand, Grossman et al. (1977); Lazear (1986); Balvers and Cosimano (1990); Trefler (1993); and Braden and Oren (1994) develop economic models for learning the demand curve, but they assume that the stocking quantity is given rather than incorporate it as a decision variable.

A fourth stream of literature is that on procurement models with recourse. This literature has become vast in recent years, thanks to the explosive interest in supply chain management. We provide only representative samples of related models here and refer the reader to Tayur, Ganeshan, and Magazine (1999) for a more comprehensive treatment. Briefly stated, models of this type investigate postponement strategies in which a buyer retains procurement flexibility by placing a tentative order with a supplier only to adjust that order at a later time once more accurate market information becomes available. Academic interest typically is in the development of contract parameters defining the degree of flexibility afforded to the buyer and in the "price" of flexibility; that is, in the form and amount of compensation provided by the buyer to the supplier in exchange for the flexibility to the adjust the procurement amount. Common subject headings appearing in this literature include accurate response (e.g., Fisher and Raman, 1996); backup agreements (e.g., Eppen and Iyer, 1997); buyback or returns policies (e.g., Emmons and Gilbert, 1998); minimum quantity commitments (e.g., Bassok and Anupindi, 1997); quantity flexibility (e.g., Tsay and Lovejoy, 1999); quick response (Iyer and Bergen, 1997); and global sourcing (Kouvelis and Gutierrez, 1997).

Kouvelis and Gutierrez (1997) were particularly influential in the development of our model. They develop a profit-maximizing strategy for an international firm that sells a fashion good in two, nonoverlapping markets. In their model, Kouvelis and Gutierrez incorporate foreign exchange risk and provide the alternative of transferring to the second market some portion of the leftovers remaining from 
the first market; however, they assume that the selling price for each market is given and that the demand distribution is not updated between periods. Kouvelis and Gutierrez focus primarily on devising a wholesale pricing scheme for the transfer of inventory between the two markets so as to find an efficient allocation of profit between the players participating in the two markets. We focus instead on a retail pricing scheme for the transfer of information between the two markets so as to optimize the coordinated profit generated by the two markets combined.

\section{Formulation of the Two-Period Stochastic Program}

Consider a single firm that operates in two retail markets. The firm offers the same product for sale in both markets, but the selling seasons are non-overlapping. Consequently, the firm can transfer some or all of the leftovers remaining from the first market to the second market for possible sale in the second selling season. In addition, the respective market demand functions, each of which are stochastic, price dependent, and include an uncertain intercept term, are related due to homogenous customer preferences. As a result, the firm can revise its characterization of the unknown demand parameter applicable to the second market by gathering information about demand in the first market and then transferring that information to the second market. The firm's objective is to maximize the total expected profit generated by the two markets; it's controls are the stocking quantity and the retail selling price for each of the two markets.

We define the following basic notation for our model:

$i=1,2$ : index identifying the first and second retail markets, respectively; or equivalently, index identifying the first and second selling periods, respectively.

$p_{i}: \quad$ per-unit selling price of stock available for retail sale in market $i$.

Q: $\quad$ quantity ordered at the beginning of period 1 (from an outside supplier), but not received until the beginning of period 2 .

$\mathrm{q}_{1}$ : amount of $\mathrm{Q}$ that is stocked for retail sale in market $2\left(\mathrm{q}_{1}\right.$ represents a recourse decision; $\mathrm{q}_{1}<\mathrm{Q}$ indicates a recourse decision to discard $\mathrm{Q}-\mathrm{q}_{1}$ units rather than to make them available for retail sale in market 2).

q12: quantity remaining at the end of period 1 (from operations in market 1 ) that is carried into period 2 and stocked for retail sale in market 2 . 

$\mathrm{q}_{2}:$
quantity purchased (from an outside supplier) at the beginning of period 2 that is stocked for retail sale in market 2 .
$S_{\mathrm{i}}$ : $\quad$ stocking quantity made available for retail sale in market $i\left(S_{1}\right.$ is ordered and purchased from an outside supplier at the beginning of period $1 ; S_{2}=q_{1}+q_{12}+q_{2}$ ).
$c_{i}$ : $\quad$ per-unit purchase cost associated with stock ordered at the beginning of period $i$.
$c_{12}$ : per-unit transshipment cost associated with transferring stock left over from market 1 to market 2 (applies only if markets are separated in space as, for example, in the global newsvendor problem).
$h_{\mathrm{i}}$ : $\quad$ per-unit holding cost attributed to inventory left over in period $\mathrm{i}$.
$\varepsilon_{i}$ : $\quad$ random variable representing the uncertainty associated with the demand function corresponding to market $i$.
$D\left(\mathrm{p}_{\mathrm{i}}, \varepsilon_{\mathrm{i}}\right)$ : uncertain, price-dependent demand function corresponding to market $\mathrm{i}$.
$\mathrm{L}_{\mathrm{i}}: \quad$ number of leftovers from market $\mathrm{i}\left(\mathrm{L}_{\mathrm{i}}=\max \left\{\mathrm{S}_{\mathrm{i}}-\mathrm{D}\left(\mathrm{p}_{\mathrm{i}}, \varepsilon_{\mathrm{i}}\right), 0\right\}\right)$.
$\ell$ : $\quad$ realized number of leftovers from market 1 ; this establishes the maximum amount of inventory that can be transferred from market 1 to market 2 .
$\mathrm{t}$. $\quad$ sufficient statistic representing information obtained during the first selling season and used to update the characterization of $\varepsilon_{2}$; this information is deduced from $\ell$.
$\mu_{1}, \mu_{2}(t)$ : expected value of $\varepsilon_{1}$ and $\varepsilon_{2}$ (given the information $t$ ), respectively.
$F_{1}(),. F_{2}(. \mid t)$ : distribution function associated with $\varepsilon_{1}$ and $\varepsilon_{2}$ (given the information $t$ ), respectively.
$f_{1}(),. f_{2}(\cdot t)$ density function associated with $\varepsilon_{1}$ and $\varepsilon_{2}$ (given the information $t$ ), respectively.

We assume that the firm commits to procurement quantities for both markets at the beginning of the first selling season, although additional units can be procured for the second market at the beginning of period 2 , if necessary. We do not require that the firm receive both its procurement quantities ordered at the beginning of the first selling season, only that it establish at that time a contractual arrangement governing the specified amount to be delivered at the start of each selling season. One motivation for this restriction is the desire to establish a modeling framework for a firm that negotiates a cost discount schedule by bringing larger procurement quantities to the bargaining table. Correspondingly, we assume $c_{1}<c_{2}$, regardless of whether units purchased for $c_{2}$ are procured from the same supplier as the units purchased for $c_{1}$ or from a separate supplier altogether. Moreover, we assume that $c_{12}<c_{2}$ because otherwise, it would not be economically sensible to transfer any leftovers from market 1 to market 2 . 
We assume no penalty cost for a lost sale other than forfeited profit. That is, we let the per-unit goodwill cost of a shortage equal zero. We justify this assumption in two ways. First, each of the two markets has only one selling season; consequently, goodwill cost has little meaning. Second, the firm is a price-setter. This means that the firm affects demand by changing its selling price. Therefore, the lost goodwill resulting in an unsatisfied demand can be thought of within the context of the parameters of the demand function. Note, however, a per-unit cost of goodwill can be included explicitly in the model without changing the structure of the results. Similarly, we assume that the cost of discarding a unit is zero and that there is no salvage value. Again, either a per-unit discarding cost or a per-unit salvage value can be included without difficulty.

We characterize demand for each market as a decreasing linear function of $\mathrm{p}_{\mathrm{i}}$ and include the unknown parameter, $\varepsilon_{\mathrm{i}}$, as an additive term: $D\left(\mathrm{p}_{\mathrm{i}}, \varepsilon_{\mathrm{i}}\right)=\mathrm{a}_{\mathrm{i}}-\mathrm{b}_{\mathrm{i}} \mathrm{p}_{\mathrm{i}}+\varepsilon_{\mathrm{i}}$. We assume that $\varepsilon_{\mathrm{i}}>0$. Moreover, we assume that $\varepsilon_{1}$ and $\varepsilon_{2}$ are related such that the information transferred from the first selling season to the second selling season can be obtained by observing the number of leftovers occurring in market 1 . In particular: If leftovers remain at the end of the first selling season (i.e., if $L_{1}=S_{1}-D\left(p_{1}, \varepsilon_{1}\right)>0$ ), then market 1 sales equals market 1 demand, which implies that the realized value of $\varepsilon_{1}$ can be deduced: $\varepsilon_{1}=$ $S_{1}-a_{1}+b_{1} p_{1}-L_{1}$. In this case, the realized value of $\varepsilon_{1}$ represents the information obtained during the first selling season (i.e., if the realized value of $\varepsilon_{1}$ can be deduced, then $t=\varepsilon_{1}$ ). This information then can be used to update the demand distribution for market $2: F_{2}(. \mid t)=F_{2}\left(. \mid \varepsilon_{1}\right)$. If no leftovers remain at the end of the first selling season (i.e., if $\mathrm{L}_{1}=0$ ), then market 1 sales does not equal market 1 demand, which implies that the realized value of $\varepsilon_{1}$ cannot be deduced. However, a lower bound for $\varepsilon_{1}$, which we denote as $z_{1}$, can be deduced: $z_{1} \equiv S_{1}-a_{1}+b_{1} p_{1}$. In this case, the lower bound for $\varepsilon_{1}$ represents the information obtained during the first selling season (i.e., if the realized value of $\varepsilon_{1}$ cannot be deduced, then $t=z_{1}$, where $z_{1}$ provides a lower bound for $\varepsilon_{1}$ ). This information then can be used to update the demand distribution for market $2: F_{2}(\cdot \mid t)=F_{2}\left(\cdot \mid z_{1}\right)$. We introduce a specific technique for using t to derive $F_{2}(. \mid t)$ in Section 4. 
Regardless of the events occurring during the first selling season, the decisions that are made at the beginning of the second selling season are made in the presence of uncertainty. However, because $\varepsilon_{2}$ is related to $\varepsilon_{1}$, the characterization of that uncertainty can be honed by using information revealed during the first selling season. Such information comes in one of two possible forms, depending on whether or not leftovers remain at the conclusion of the first selling season: If leftovers remain, then $t=\varepsilon_{1}$, which represents an example of full (or complete) information being transferred from market 1 to market 2 . If leftovers do not remain, then $t=z_{1}$ represents an example of censored information being transferred from market 1 to market 2 . We refer to the quantity, $z_{i}$, defined in general as $z_{i}=S_{i}-a_{i}+b_{i} p_{i}$, as the stocking factor associated with selling season i (Petruzzi and Dada, 1999a). It is a convenient measure because a simple comparison between $z_{i}$ and $\varepsilon_{i}$ yields the number of leftovers in selling season $i: L_{i}=$ $\max \left\{z_{i}-\varepsilon_{i}, 0\right\}$.

Next, we present our model formally. Let:

$\pi \quad=$ maximum expected profit associated with the two-period problem.

$\Pi\left(Q, z_{1} \mid t\right)=$ maximum expected profit associated with the recourse problem when $Q$ is the procurement quantity for market 2 committed to prior to the first selling season, $z_{1}$ is the stocking factor associated with market 1 , and $t$ is the information obtained during the first selling season.

At the beginning of the first selling season, $Q$ units are ordered for delivery at the beginning of the second selling season at a cost of $c_{1}$ each. Although these units are not available for sale in market 1 and, perhaps, are not paid for until the beginning of the second selling season, the decision must be made at the beginning of the first season. Thus, we account for their cost in period 1. Also at the beginning of the first selling season, $S_{1}$ units are purchased at a cost of $c_{1}$ each. These units are stocked for sale in market 1 . Each unit sold in market 1 generates a revenue of $\mathrm{p}_{1}$ and each unit left over creates a holding cost of $h_{1}$. Then, at the beginning of the second selling season, $S_{2}$ units are stocked for sale in market 2. Of the $S_{2}$ units stocked, $q_{1}$ units are acquired at no additional marginal cost (the "purchase" cost associated with $q_{1}$ is zero because the investment in this stock is sunk, committed to a period earlier), but $q_{1}$ is restricted by $Q$, the quantity ordered one period earlier; $q_{12}$ units are acquired for $a$ 
marginal cost of $c_{12}$ each, but $q_{12}$ is restricted by $L_{1}=\max \left\{z_{1}-\varepsilon_{1}, 0\right\}$, the random number of leftovers remaining at the end of the first selling season; and $q_{2}$ units are purchased for a marginal cost of $c_{2}$ each (there is no capacity limitation for $\mathrm{q}_{2}$ ). Each unit sold in market 2 generates a revenue of $\mathrm{p}_{2}$ and each unit left over creates a holding cost of $\mathrm{h}_{2}$. Thus, using the identity sales $=$ stocking quantity -leftovers and applying the definitions $S_{2}=q_{1}+q_{I 2}+q_{2}$ and $z_{i}=S_{i}-a_{i}+b_{i} p_{i}$ for $\mathrm{i}=1$ and 2 , we can write:

$$
\pi=\max _{p_{1}, S_{1}, Q}\left\{\left[p_{1} S_{1}-\left(p_{1}+h_{1}\right) \int_{0}^{z_{1}} F_{1}\left(x_{1}\right) d x_{1}-c_{1}\left(S_{1}+Q\right)\right]+E\left[\Pi\left(Q, z_{1}\right)\right]\right\}
$$

where,

$$
\dot{\mathrm{E}}\left[\Pi\left(\mathrm{Q}, \mathrm{z}_{1}\right)\right]=\int_{0}^{z_{1}} \Pi\left(\mathrm{Q}, \mathrm{z}_{1} \mid \mathrm{t}=\mathrm{x}_{1}\right) \mathrm{f}_{1}\left(\mathrm{x}_{1}\right) \mathrm{dx_{1 }}+\Pi\left(\mathrm{Q}, \mathrm{z}_{1} \mid \mathrm{t}=\mathrm{z}_{1}\right)\left[1-\mathrm{F}_{1}\left(\mathrm{z}_{1}\right)\right]
$$

and

$$
\Pi\left(Q, z_{1} \mid t\right)=\max _{\substack{p_{2}, q_{2}, q_{1} \leq Q \\ q_{12} \leq z_{1}-t}}\left\{p_{2} S_{2}-\left(p_{2}+h_{2}\right) \int_{0}^{z_{2}} F_{2}\left(x_{2} \mid t\right) d x_{2}-\left(c_{12} q_{12}+c_{2} q_{2}\right)\right\}
$$

In (1), the expression in brackets represents the expected profit attributed to the decisions made at the beginning of the first selling season, and $E\left[\Pi\left(Q, z_{1}\right)\right]$ represents the expected profit attributed to the second selling season, which is based on the understanding that information obtained from market 1 is transferred to market 2 and that an optimal policy then is followed in market 2 . In (2) and (3), $t$ denotes the information obtained in market 1 and transferred to market 2: If leftovers remain at the end of the first selling season, then $t$ denotes the realized value of $\varepsilon_{1}$ that is inferred; if leftovers do not remain, then $t$ denotes the lower bound for $\varepsilon_{1}$ that is inferred (namely, $z_{1}$ ). In either case, $\ell=z_{1}-t$ indicates the realized number of leftovers from market 1 , which establishes the maximum number of units available for transfer to market 2 .

The objective is to solve (1) and thereby determine the optimal decision policy for market 1 , which we denote as $\left(\mathrm{p}_{1}{ }^{*}, \mathrm{~S}_{1} *, \mathrm{Q}^{*}\right)$. However, solving (1) requires the computation of (2), which requires first solving (3), the recourse problem. Thus, solving (1) requires the determination of the conditional optimal decision policy for market 2 , which depends on $t$, the information obtained during the first selling season. We denote the conditional optimal decision policy for market 2 as $\left(\mathrm{p}_{2}{ }^{*}, \mathrm{q}_{1}{ }^{*}, \mathrm{q}_{12}{ }^{*}, \mathrm{q}_{2}{ }^{*}\right)$. 


\section{Analysis of the Recourse Problem}

In this section, we analyze the recourse problem using a two-step procedure: First, we determine $\left(\mathrm{p}_{2}{ }^{*}, \mathrm{q}_{1}{ }^{*}, \mathrm{q}_{12}{ }^{*}, \mathrm{q}_{2}{ }^{*}\right)$, the conditionally-optimal solution to (3), given $\mathrm{t}$, the information obtained during the first selling season; and second, we compute (2), the expected profit associated with the solution to (3), by un-conditioning on $t$. Then, we incorporate foreign exchange risk into the analysis to demonstrate the recourse problem as an extension to the global newsvendor problem. And, we close with a discussion of the more general applicability of the recourse solution.

\section{Determining the Recourse Decisions}

Since the manager making the recourse decisions has three distinct sources from which to establish the desired stocking quantity for market 2 , the recourse decision problem can be viewed as a three-supplier generalization of the newsvendor problem with pricing. Recall that the stocking quantity for market 2 is $S_{2}=q_{1}+q_{12}+q_{2}$. The quantity $q_{2}$ is purchased from a supplier who has unlimited capacity. The constant marginal cost of these units is $c_{2}$. The quantity $q_{12}$ is purchased from a "supplier" who has random capacity $L_{1}$, although the value of $L_{1}$ is realized prior to the determination of $q_{12}$. ( $L_{1}$ refers to the number of leftovers from market 1.) The constant marginal cost of these units is $c_{12}$. Finally, the quantity $\mathrm{q}_{1}$ is purchased from a supplier who has fixed capacity $\mathrm{Q}$. The constant marginal cost of these units is $c_{0}$. (In the recourse problem described in Section 2, $c_{0} \equiv 0$. However, we introduce $c_{0}$ here to complete the generalization.) Recall, the right to purchase up to $\mathrm{Q}$ units from this supplier is purchased for $c_{1} Q$ prior to the start of the first selling season.

Given this generalized description, (3) can be written as follows:

$$
\begin{aligned}
& \Pi\left(Q, z_{1} \mid t\right)=\max _{p_{2}, q_{1}, q_{12}, q_{2}} R\left(p_{2}, q_{1}, q_{12}, q_{2} \mid t\right) \\
& \text { s.t. } q_{1} \leq Q \\
& q_{12} \leq L_{1}
\end{aligned}
$$

where,

$$
R\left(p_{2}, q_{1}, q_{12}, q_{2} \mid t\right)=p_{2} S_{2}-\left(p_{2}+h_{2}\right) \int_{0}^{z_{2}} F_{2}\left(x_{2} \mid t\right) d x_{2}-\left(c_{0} q_{1}+c_{12} q_{12}+c_{2} q_{2}\right)
$$

and, recall: 


$$
\begin{aligned}
& \mathrm{S}_{2}=\mathrm{q}_{1}+\mathrm{q}_{12}+\mathrm{q}_{2} \\
& \mathrm{z}_{2}=\mathrm{S}_{2}-\mathrm{a}_{2}+\mathrm{b}_{2} \mathrm{p}_{2} \\
& \mathrm{~L}_{1}=\mathrm{z}_{1}-\mathrm{t} \\
& 0=c_{0}<\mathrm{c}_{12}<\mathrm{c}_{2}
\end{aligned}
$$

Relationship (9) establishes a preference among sources of stock for market 2. Strictly speaking, there may be no preference between the source that charges the per-unit cost $c_{0}$ and the source that charges the per-unit cost $c_{12}$ (if $c_{12}=c_{0}=0$ ); however this would represent a degenerate case in which the threesupplier generalization collapses to a two-supplier generalization. In such a case, one source of supply would charge $c_{2}$ and would have unlimited capacity, and the other source of supply would charge $c_{0}=$ $c_{12}$ and would have a capacity limit of $Q+L_{1}$ units. Since the analysis of the two-supplier generalization is analogous to the analysis of the three-supplier generalization, we assume that the preference between $c_{0}$ and $c_{12}$ is strict. Thus, (9) implies that no units should be acquired at a per-unit cost of $c_{12}$ unless $Q$ units are acquired at a per-unit cost of $c_{0}$; and, no units should be acquired at a perunit cost of $c_{2}$ unless $L_{1}$ units are acquired at a per-unit cost of $c_{12}$.

In other words, in determining how many units should be acquired for market 2 from each of the three sources of supply; it is sufficient to choose only $S_{2}$, the total stocking quantity. We state this observation formally as Lemma 1.

LEMMA 1. Given a choice for $S_{2}$, the optimal allocation of this stocking quantity among the three sources of stock is:

$$
\left(q_{1}^{*}, q_{12}^{*}, q_{2}^{*}\right) \mid S_{2} \equiv\left(q_{1}\left(S_{2}\right), q_{12}\left(S_{2}\right), q_{2}\left(S_{2}\right)\right)= \begin{cases}\left(S_{2}, 0,0\right) & \text { if } S_{2} \leq Q \\ \left(Q, S_{2}-Q, 0\right) & \text { if } Q<S_{2} \leq Q+L_{1} \\ \left(Q, L_{1}, S_{2}-Q-L_{1}\right) & \text { if } Q+L_{1}<S_{2}\end{cases}
$$

This result leads to Lemma 2, the proof for which is in the appendix.

LEMMA 2. Given $t$, the optimal selling price and the optimal stocking quantity for market 2 can be determined as functions of $\mathrm{z}_{2}$ as follows: 
(a)

$$
\begin{aligned}
& \mathrm{p}_{2} * \mid \mathrm{S}_{2} \equiv \mathrm{p}_{2}\left(\mathrm{z}_{2} \mid \mathrm{t}\right)=\frac{\mathrm{a}_{2}+\mathrm{z}_{2}-\Lambda_{2}\left(\mathrm{z}_{2} \mid \mathrm{t}\right)-\mathrm{b}_{2} \mathrm{~h}_{2} \mathrm{~F}_{2}\left(\mathrm{z}_{2} \mid \mathrm{t}\right)}{\mathrm{b}_{2}\left[1+\mathrm{F}_{2}\left(\mathrm{z}_{2} \mid \mathrm{t}\right)\right]} \\
& \mathrm{S}_{2}{ }^{*} \mid \mathrm{z}_{2} \equiv \mathrm{S}_{2}\left(\mathrm{z}_{2} \mid \mathrm{t}\right)=\frac{\Lambda_{2}\left(\mathrm{z}_{2} \mid \mathrm{t}\right)+\left(\mathrm{a}_{2}+\mathrm{b}_{2} \mathrm{~h}_{2}+\mathrm{z}_{2}\right) \mathrm{F}_{2}\left(\mathrm{z}_{2} \mid \mathrm{t}\right)}{1+\mathrm{F}_{2}\left(\mathrm{z}_{2} \mid \mathrm{t}\right)}
\end{aligned}
$$

where $\Lambda_{2}\left(z_{2} \mid t\right) \equiv \int_{0}^{z_{2}} F_{2}\left(x_{2} \mid t\right) d x_{2}$ represents the expected number of leftovers in market 2 . .

Lemma 2(a) provides a simple prescription for computing the optimal selling price for market 2, if a value for $S_{2}$ is given. One interesting property of this prescription is that $p_{2}{ }^{*} \mid S_{2}$ can be expressed solely as a function of $z_{2}$, the stocking factor for market 2 . Given this property, the stocking quantity for market 2 also can be expressed as a function of the market 2 stocking factor (Lemma 2(b)).

Thus, the problem of determining $\left(\mathrm{p}_{2}^{*}, \mathrm{q}_{1}{ }^{*}, \mathrm{q}_{12}{ }^{*}, \mathrm{q}_{2}{ }^{*}\right)$, the optimal decision vector for the second selling period, reduces to an optimization problem over a single variable. Specifically, (4) can be transformed into a problem written strictly as a function of $z_{2}$ :

$$
\begin{aligned}
& \Pi\left(Q, z_{1} \mid t\right)=\max _{z_{2}} R\left(z_{2} \mid t\right) \\
& \text { s.t. } \quad q_{1}\left(z_{2} \mid t\right) \leq Q \\
& q_{12}\left(z_{2} \mid t\right) \leq L_{1}
\end{aligned}
$$

where,

$$
R\left(z_{2} \mid t\right)=p_{2}\left(z_{2} \mid t\right) S_{2}\left(z_{2} \mid t\right)-\left(p_{2}\left(z_{2} \mid t\right)+h_{2}\right) \Lambda_{2}\left(z_{2} \mid t\right)-\left(c_{0} q_{1}\left(z_{2} \mid t\right)+c_{12} q_{12}\left(z_{2} \mid t\right)+c_{2} q_{2}\left(z_{2} \mid t\right)\right)
$$

and where $q_{j}\left(z_{2} \mid t\right)$ is short for $q_{j}\left(S_{2}\left(z_{2} \mid t\right)\right)$, for $j=1,12$, and 2. Let $z_{2} *$ denote the solution to $(10)$. Then the optimal recourse policy can be recovered as follows: from Lemma $2(a), \mathrm{p}_{2} *=\mathrm{p}_{2}\left(\mathrm{z}_{2} * \mid t\right)$ and, from Lemma $1,\left(\mathrm{q}_{1}{ }^{*}, \mathrm{q}_{12}{ }^{*}, \mathrm{q}_{2}{ }^{*}\right)=\left(\mathrm{q}_{1}\left(\mathrm{~S}_{2}\left(\mathrm{z}_{2} * \mid \mathrm{t}\right)\right), \mathrm{q}_{12}\left(\mathrm{~S}_{2}\left(\mathrm{z}_{2} * \mid \mathrm{t}\right)\right), \mathrm{q}_{2}\left(\mathrm{~S}_{2}\left(\mathrm{z}_{2} * \mid \mathrm{t}\right)\right)\right)$, where $\mathrm{S}_{2}\left(\mathrm{z}_{2} * \mid \mathrm{t}\right)$ is obtained from Lemma 2(b).

To solve (10) and thus, to determine $\mathrm{z}_{2}{ }^{*}$, we establish and interpret a series of lemmas, the proofs for which are provided in the appendix.

LEMMA 3. There exists a $z_{2}$, say $z_{Q}$, that is such that $S_{2}\left(z_{2} \mid t\right)<Q$ if and only if $z_{2}<z_{Q}$. Likewise, there exists a $z_{2}$, say $z_{Q+L}$, that is such that $S_{2}\left(z_{2} \mid t\right)<Q+L_{1}$ if and only if $z_{2}<z_{Q+L}$. Moreover, $\mathrm{z}_{\mathrm{Q}} \leq \mathrm{z}_{\mathrm{Q}+\mathrm{L}}$. 
LEMMA 4. . Define $M\left(z_{2} \mid t\right)=\left[p_{2}\left(z_{2} \mid t\right)+h_{2}\right]\left[1-F_{2}\left(z_{2} \mid t\right)\right]$. If

(a) $a_{2}>b_{2} c_{2}$; and

(b) $\partial g_{2}\left(z_{2} \mid t\right) / \partial z_{2}+2 g_{2}\left(z_{2} \mid t\right)^{2}>0$, where $g_{2}\left(z_{2} \mid t\right) \equiv f_{2}\left(z_{2} \mid t\right) /\left[1-F_{2}\left(z_{2} \mid t\right)\right]$ is the hazard rate associated with $\varepsilon_{2}$;

then, there exists a $z_{2}$, say $z_{\text {III }}$, that is such that $M\left(z_{2} \mid t\right)>c_{2}+h_{2} \Leftrightarrow z_{2}<z_{\text {III }}$; there exists a $z_{2}$, say $z_{n}$, that is such that $M\left(z_{2} \mid t\right)>c_{12}+h_{2} \Leftrightarrow z_{2}<z_{I I}$; and there exists a $z_{2}$, say $z_{1}$, that is such that $\mathrm{M}\left(\mathrm{z}_{2} \mid \mathrm{t}\right)>\mathrm{c}_{0}+\mathrm{h}_{2} \Leftrightarrow \mathrm{z}_{2}<\mathrm{z}_{\mathrm{I}}$. Moreover, $\mathrm{z}_{\mathrm{III}}<\mathrm{z}_{\mathrm{II}}<\mathrm{z}_{\mathrm{I}}$.

Lemmas 3 and 4 provide mathematical properties useful for solving (10). In addition, Lemma 2 introduces conditions to ensure tractability: Condition (a) provides some assurance that market 2 demand is positive. And, Condition (b) establishes a tractability test for the recourse problem. It will be satisfied, for example, if $\varepsilon_{2}$ is characterized by a distribution having a non-decreasing hazard rate.

Distributions having a non-decreasing hazard rate are commonplace (see Barlow and Proschan, 1965, for examples); however, it is not enough simply to assume at the onset that $\mathrm{F}_{2}(. \mid \mathrm{t})$ is such a distribution. This is because $\mathrm{F}_{2}(\cdot \mathrm{t})$ is not constructed until after information is gathered from the first selling season. Moreover, $F_{2}(. \mid t)$ depends on the type of information gathered (full or censored). As a result, the properties of $F_{2}(. t)$ are sensitive to the specific construct by which $\varepsilon_{1}$ and $\varepsilon_{2}$ are related. For now, we assume that Condition (b) holds so that we may proceed; and then, in Section 4, we identify conditions to assure that this assumption is valid.

Next, we note from Lemma 3 that, for a given $t, z_{Q} \leq z_{Q+L}$. And, we note from Lemma 4 that, for a given $\mathrm{t}, \mathrm{z}_{\mathrm{III}}<\mathrm{z}_{\mathrm{II}}<\mathrm{z}_{\mathrm{I}}$. However, $\mathrm{z}_{2}{ }^{*}$ and consequently, the optimal recourse policy $\left(\mathrm{p}_{2}{ }^{*}, \mathrm{q}_{1}{ }^{*}, \mathrm{q}_{12}{ }^{*}, \mathrm{q}_{2}{ }^{*}\right)$ depends on how $z_{Q+L}$ and $z_{Q}$ are related to $z_{l}, z_{\mathrm{ll}}$, and $z_{m}$. We tabulate the possibilities and the corresponding results in Lemma 5. The technical details are provided in the appendix.

\section{LEMMA 5. Let:}

$$
\begin{aligned}
& R_{1}\left(z_{2} \mid t\right) \equiv\left(p_{2}\left(z_{2} \mid t\right)-c_{0}\right) S_{2}\left(z_{2} \mid t\right)-\left(p_{2}\left(z_{2} \mid t\right)+h_{2}\right) \Lambda_{2}\left(z_{2} \mid t\right) \\
& R_{I I}\left(z_{2} \mid t\right) \equiv\left(p_{2}\left(z_{2} \mid t\right)-c_{12}\right) S_{2}\left(z_{2} \mid t\right)-\left(p_{2}\left(z_{2} \mid t\right)+h_{2}\right) \Lambda_{2}\left(z_{2} \mid t\right)+\left(c_{12}-c_{0}\right) Q \\
& R_{I I I}\left(z_{2} \mid t\right) \equiv\left(p_{2}\left(z_{2} \mid t\right)-c_{2}\right) S_{2}\left(z_{2} \mid t\right)-\left(p_{2}\left(z_{2} \mid t\right)+h_{2}\right) \Lambda_{2}\left(z_{2} \mid t\right)+\left(c_{2}-c_{0}\right) Q+\left(c_{2}-c_{12}\right) L_{1}
\end{aligned}
$$

Then, $\mathrm{z}_{2}{ }^{*}$ and the corresponding conditionally-optimal expected recourse profit can be computed as follows: 


\begin{tabular}{|c|c|c|}
\hline IF... & THEN, $z_{2} *=$ & $\mathrm{AND}, \Pi\left(\mathbf{Q}, \mathrm{z}_{1} \mid t\right)=$ \\
\hline $\mathrm{z}_{\mathrm{Q}+\mathrm{L}} \leq \mathrm{z}_{\mathrm{II}}$ & ZIII & $\mathrm{R}_{\text {III }}\left(\mathrm{z}_{\text {III }} \mid t\right)$ \\
\hline $\mathrm{z}_{\mathrm{III}}<\mathrm{z}_{\mathrm{Q}+\mathrm{L}}<\mathrm{z}_{\mathrm{II}}$ & $\mathrm{z}_{\mathrm{Q}+\mathrm{L}}$ & $\mathrm{R}_{I I}\left(\mathrm{z}_{\mathrm{Q}+\mathrm{L}} \mid \mathrm{t}\right)$ \\
\hline $\mathrm{z}_{\mathrm{Q}} \leq \mathrm{z}_{\mathrm{II}} \leq \mathrm{z}_{\mathrm{Q}+\mathrm{L}}$ & $\mathrm{z}_{\text {II }}$ & $R_{\Pi}\left(z_{\Pi} \mid t\right)$ \\
\hline $\mathrm{z}_{\mathrm{II}}<\mathrm{z}_{\mathrm{Q}}<\mathrm{z}_{\mathrm{I}}$ & $\mathrm{z}_{\mathrm{Q}}$ & $\mathrm{R}_{\mathrm{I}}\left(\mathrm{z}_{\mathrm{Q}} \mid \mathrm{t}\right)$ \\
\hline $\mathrm{z}_{\mathrm{I}} \leq \mathrm{z}_{\mathrm{Q}}$ & $\mathrm{z}_{\mathrm{I}}$ & $\mathrm{R}_{\mathrm{I}}\left(\mathrm{z}_{\mathrm{I}} \mid \mathrm{t}\right)$ \\
\hline
\end{tabular}

Together, Lemmas 1-5 imply a procedure for solving the recourse problem optimally. Next, we summarize this conditionally-optimal policy, as well as the procedure for determining it. Then, we interpret and discuss the policy.

THEOREM 1. If, for a given $t$, conditions (a) and (b) of Lemma 4 are satisfied, then $\left(\mathrm{p}_{2}{ }^{*}, \mathrm{q}_{1}{ }^{*}, \mathrm{q}_{12}{ }^{*}, \mathrm{q}_{2}{ }^{*}\right)$, the conditionally-optimal recourse policy, can be determined as follows:

$I^{\text {st }}$ Obtain $\mathrm{t}$ from market 1 and use it to construct $S_{2}\left(\mathrm{z}_{2} \mid \mathrm{t}\right)$ from Lemma $2(\mathrm{~b})$ and $\mathrm{M}\left(\mathrm{z}_{2} \mid \mathrm{t}\right)$ from Lemma 4. Also, use it to determine $L_{1}$ from (8).

$2^{\text {nd }}$ Compute $\mathrm{z}_{\mathrm{Q}}, \mathrm{z}_{\mathrm{Q}+\mathrm{L}}, \mathrm{z}_{\mathrm{I}}, \mathrm{z}_{\mathrm{l}}$, and $\mathrm{z}_{\mathrm{III}}$ as the unique solutions to $\mathrm{S}_{2}\left(\mathrm{z}_{\mathrm{Q}} \mid \mathrm{t}\right)=\mathrm{Q}, \mathrm{S}_{2}\left(\mathrm{z}_{\mathrm{Q}+\mathrm{L}} \mid \mathrm{t}\right)=$ $\mathrm{Q}+\mathrm{L}_{1}, \mathrm{M}\left(\mathrm{z}_{\mathrm{III}} \mid \mathrm{t}\right)=\mathrm{c}_{2}+\mathrm{h}_{2}, \mathrm{M}\left(\mathrm{z}_{\mathrm{II}} \mid \mathrm{t}\right)=\mathrm{c}_{12}+\mathrm{h}_{2}$, and $\mathrm{M}\left(\mathrm{z}_{1} \mid \mathrm{t}\right)=\mathrm{c}_{0}+\mathrm{h}_{2}$, respectively.

$3^{\text {rd }}$ Sort $\mathrm{z}_{\mathrm{Q}}, \mathrm{z}_{\mathrm{Q}+\mathrm{L}}, \mathrm{z}_{\mathrm{I}}, \mathrm{z}_{\mathrm{II}}$, and $\mathrm{z}_{\mathrm{III}}$, and then determine $\mathrm{z}_{2}{ }^{*}$ from Lemma 5 .

$4^{\text {th }}$ Compute $\mathrm{S}_{2}{ }^{*}$ and $\mathrm{p}_{2}$ * from Lemma 2 as follows:

\begin{tabular}{|c|c|c|}
\hline If $z_{2}{ }^{*}=$ & Then, $S_{2}{ }^{*}=$ & And, $p_{2}{ }^{*}=$ \\
\hline$z_{\text {III }}$ & $b_{2}\left(p_{2}{ }^{*}-c_{2}\right)+\Lambda_{2}\left(z_{I I I} \mid t\right)$ & $c_{2}+\left(c_{2}+h_{2}\right) \frac{F_{2}\left(z_{I I I} \mid t\right)}{1-F_{2}\left(z_{I I} \mid t\right)}$ \\
\hline$z_{Q+L}$ & $Q+L_{1}$ & $\frac{a_{2}+z_{Q+L}-\left(Q+L_{1}\right)}{b_{2}}$ \\
\hline$z_{\text {II }}$ & $b_{2}\left(p_{2}{ }^{*}-c_{12}\right)+\Lambda_{2}\left(z_{I I} \mid t\right)$ & $c_{12}+\left(c_{12}+h_{2}\right) \frac{F_{2}\left(z_{I I} \mid t\right)}{1-F_{2}\left(z_{I I} \mid t\right)}$ \\
\hline$z_{Q}$ & $Q$ & $\frac{a_{2}+z_{Q}-Q}{b_{2}}$ \\
\hline$z_{I}$ & $b_{2}\left(p_{2}{ }^{*}-c_{0}\right)+\Lambda_{2}\left(z_{I} \mid t\right)$ & $c_{0}+\left(c_{0}+h_{2}\right) \frac{F_{2}\left(z_{I} \mid t\right)}{1-F_{2}\left(z_{I} \mid t\right)}$ \\
\hline
\end{tabular}

$5^{\text {th }}$ Compute $\mathrm{q}_{1} *, \mathrm{q}_{12} *$,and $\mathrm{q}_{2} *$ from Lemma 1 as follows: $\mathrm{q}_{1} *=\min \left\{\mathrm{S}_{2} *, \mathrm{Q}\right\}, \mathrm{q}_{12} *=$ $\min \left\{\mathrm{S}_{2}{ }^{*}, \mathrm{Q}+\mathrm{L}_{1}\right\}-\mathrm{q}_{1}{ }^{*}$, and $\mathrm{q}_{2}{ }^{*}=\mathrm{S}_{2}{ }^{*}-\mathrm{q}_{1}{ }^{*}-\mathrm{q}_{2}{ }^{*}$. 
In summary, $z_{\mathrm{I}}, \mathrm{z}_{\mathrm{II}}, \mathrm{z}_{\mathrm{II}}, \mathrm{z}_{\mathrm{Q}}$, and $\mathrm{z}_{\mathrm{Q}+\mathrm{L}}$ can be computed and sorted only after $\mathrm{t}$ is obtained from market 1 . Then, depending on the results of the sorting, $z_{2}{ }^{*}$, the conditionally-optimal stocking factor for market 2, can be determined from Lemma 5 . Once $z_{2} *$ is determined, the conditionally-optimal recourse policy can be recovered by applying Lemmas 1 and 2 . The five scenarios correspond, in effect, to the "goodness" with which market 2 demand is estimated at the start of the first selling season. For example, the scenario $\mathrm{z}_{\mathrm{Q}} \geq \mathrm{z}_{1}$ corresponds to the situation in which market 2 demand initially is overestimated by a significant amount. In this scenario, the response to learning that market 2 demand is smaller than estimated is to discard all of the leftovers from market 1 and to discard a portion of $Q$, the amount initially procured for market 2 . The corresponding "cost" of making this initial overestimation of market 2 demand is the purchase cost initially paid for the units that ultimately are discarded rather than made available for sale. This type of cost is analogous to paying insurance premiums on a policy for which no claim is ever submitted.

At the other end of the spectrum, the scenario $\mathrm{z}_{\mathrm{Q}+\mathrm{L}} \leq \mathrm{z}_{\mathrm{In}}$ corresponds to the situation in which market 2 demand initially is underestimated by a significant amount. In this scenario, the response to learning that market 2 demand is larger than estimated is not only to supplement $Q$ with all of the leftovers from market 1 , but also to augment that sum with enough additional units to bring the stocking quantity for market 2 up to $S_{2}\left(z_{\text {III }} \mid t\right)$. The corresponding "cost" of making the initial underestimation of market 2 demand is the incremental purchase cost of the extra units at the premium price. This type of cost is analogous to having out-of-pocket expenses exceed the maximum coverage of an insurance policy.

Another interesting observation from Theorem 1 is the following set of interpretations regarding the optimal recourse selling price and stocking quantity: The "desired" selling price is a price that includes a mark-up over the marginal cost of purchasing the next unit, where the mark-up is set equal to the marginal cost of having the next unit be left over $\left(c_{j}+h_{2}\right)$ times the "odds" that the next unit will be left over. (Since $\mathrm{F}_{2}\left(\mathrm{z}_{2} * \mid \mathrm{t}\right)$ denotes the probability of having the next unit be left over and $1-\mathrm{F}_{2}\left(\mathrm{z}_{2} * \mid \mathrm{t}\right.$ ) denotes the probability of having the next unit not be left over, we interpret the ratio of $\mathrm{F}_{2}\left(\mathrm{z}_{2} * \mid \mathrm{t}\right)$ to 1 $\mathrm{F}_{2}\left(\mathrm{z}_{2} * \mid \mathrm{t}\right)$ as the odds that the next unit will be left over.) The corresponding desired stocking quantity is 
the amount that equates expected sales $\left(S_{2}{ }^{*}-\Lambda_{2}\left(z_{2}{ }^{*} \mid t\right)\right)$ to $b_{2}$ times the optimal mark-up in price $\left(\mathrm{p}_{2}{ }^{*}-\right.$ $c_{j}$ ). However, if the decision maker is constrained not to operate at one of the desired price/quantity combinations, then the "consolation" selling price is the price that clears the existing inventory.

\section{Computing the Expected Profit of the Recourse Problem}

In the previous subsection, we demonstrated how to determine the optimal recourse policy and the associated expected profit for the second selling period, for a given $t$. However, $\mathrm{t}$ represents information obtained from market l's operations and hence, does not become available until the conclusion of the first selling period. Since we are interested not only in behaving optimally in the second selling period, but also in behaving optimally in the first selling period given the understanding that an optimal course of action will be followed in the second selling period based on the information obtained from the first, we need to consider in expectation what will occur in the second selling period. In other words, to determine the optimal course of action for the first selling period, we need to consider $E\left[\Pi\left(Q, z_{1}\right)\right]$, which, given (2),can be obtained from Lemma 5 by un-conditioning on $t$.

Computing $E\left[\Pi\left(Q, z_{1}\right)\right]$ can be quite difficult because, given $Q$ and $z_{1}$, it involves, for every possible value of $t$ : (1) running through the procedure detailed in Theorem 1 and using the output to generate $\Pi\left(Q, z_{1} \mid t\right)$, and then (2) weighting the obtained value of $\Pi\left(Q, z_{1} \mid t\right)$ by the likelihood that $t$ will take the value used in the iteration. However, we need not make such detailed computations here. In this subsection, we ascertain analytical properties of $E\left[\Pi\left(Q, z_{1}\right)\right]$ that will prove useful (in Section 5) for analyzing the first-period decision problem and for developing insight based on that analysis.

From (8), $t=z_{1}-L_{1}$ represents information that is based on the number of leftovers remaining at the conclusion of the first selling season. But, recall that $L_{1}=\max \left\{z_{1}-\varepsilon_{1}, 0\right\}$. Thus, for any realized value of $\varepsilon_{1}$, say $x_{1}$, we get $t=\min \left\{z_{1}, x_{1}\right\}$. And, from $t$, the optimal recourse policy can be determined according to Theorem 1 and then the corresponding optimal expected profit can be determined according to Lemma 5. 
Consider, then, conditioning on the event $\varepsilon_{1}=x_{1}$. If $x_{1}<z_{1}$, then $t=x_{1}$ (in other words, if $x_{1}<z_{1}$, then $\mathrm{x}_{1}$ is observable). In this case, the realized number of leftovers is $\ell=z_{1}-x_{1}>0$. This implies that $Q+$ $\ell=\mathrm{Q}+\left(\mathrm{z}_{1}-\mathrm{x}_{1}\right)>\mathrm{Q}$ and hence, Lemma 5 indicates five possible alternatives for $\Pi\left(\mathrm{Q}, \mathrm{z}_{1} \mid \mathrm{t}=\mathrm{z}_{1}\right)$ :

$$
\Pi\left(Q, z_{1} \mid t=x_{1}\right)= \begin{cases}R_{I I I}\left(z_{I I I} \mid x_{1}\right) & \text { if } z_{Q+z_{1}-x_{I}} \leq z_{I I I} \\ R_{I I}\left(z_{Q+z_{1}-x_{1}} \mid x_{1}\right) & \text { if } z_{I I}<z_{Q+z_{1}-x_{1}}<z_{I I} \\ R_{I I}\left(z_{I I} \mid x_{1}\right) & \text { if } z_{Q} \leq z_{I I} \leq z_{Q+z_{1}-x_{1}} \\ R_{I}\left(z_{Q} \mid x_{1}\right) & \text { if } z_{I I}<z_{Q}<z_{I} \\ R_{I}\left(z_{I} \mid x_{1}\right) & \text { if } z_{I} \leq z_{Q}\end{cases}
$$

If $x_{1} \geq z_{1}$, then $t=z_{1}$ (in other words, if $x_{1} \geq z_{1}$, then $x_{1}$ is not observable). In this case, the realized number of leftovers is $\ell=0$. This implies that $Q+\ell=Q$ and hence, Table 1 indicates three possible alternatives for $\Pi\left(Q, z_{1} \mid t=z_{1}\right)$ instead of five:

$$
\Pi\left(Q, z_{1} \mid t=z_{1}\right)= \begin{cases}R_{I I I}\left(z_{I I I} \mid z_{1}\right) & \text { if } z_{Q} \leq z_{I I I} \\ R_{I}\left(z_{Q} \mid z_{1}\right) & \text { if } z_{I I I}<z_{Q}<z_{I} \\ R_{I}\left(z_{I} \mid z_{1}\right) & \text { if } z_{I} \leq z_{Q} .\end{cases}
$$

Given (12) and (13), we now establish, in Theorem 2, two basic properties of $E\left[\Pi\left(Q, z_{1} \mid t\right)\right]$ that we use in Section 5 when analyzing the first-period decision problem. The proof is provided in the appendix.

THEOREM 2. (a) Given $\mathrm{z}_{1}, \mathrm{E}\left[\Pi\left(\mathrm{Q}, \mathrm{z}_{1}\right)\right]$ is non-decreasing and concave in $\mathrm{Q}$.

(b) Given $Q$, if $\partial F_{2}\left(x \mid t=z_{1}\right) / \partial z_{1} \leq 0$, then $E\left[\Pi\left(Q, z_{1}\right)\right]$ is non-decreasing in $z_{1}$.

In Theorem 2(b), the condition that $F_{2}\left(x \mid t=z_{1}\right)$ be non-increasing in $z_{1}$ is a natural one. It would be satisfied, for example, if the relationship between market 1 demand and market 2 demand were such that a larger realized demand in market 1 corresponded to a probabilistically larger demand in market 2 . In Section 4 , we specify a construct relating $\varepsilon_{1}$ and $\varepsilon_{2}$; and, in doing so, we identify conditions that assure not only that Lemma 4, Condition (b) will be satisfied, but also that the condition in Theorem 2(b) will be satisfied. 


\section{Incorporating Foreign Exchange Risk}

As indicated in the introduction, one potential application of the modeling approach presented in this paper is the global newsvendor problem. In such an application, a risk arises due to fluctuations in foreign exchange rates. In this subsection, we introduce a method for modeling foreign exchange risk that preserves the validity of Theorem 2. Like Kouvelis and Gutierrez (1997), we assume that the foreign exchange rate can be observed before the recourse decisions are made.

Suppose market 2 is in a country foreign to the home country (where market 1 is in the home country) so that demand for market 2 is a function of the selling price, when the selling price is stated in units of the foreign currency. Thus, if $\mathrm{p}_{2}$ is set in the currency of the home country, say US\$, then demand for market 2 is determined after first converting $p_{2}$ into the foreign currency: $D\left(p_{2}, \varepsilon_{2}\right)=a_{2}-b_{2}\left(\eta p_{2}\right)+\varepsilon_{2}$, where $\eta$ denotes the random foreign exchange rate. If we let $\beta_{2} \equiv b_{2} \eta$, then this demand function is equivalent to the demand function used previously for market $2\left(D\left(p_{2}, \varepsilon_{2}\right)=a_{2}-\beta_{2} p_{2}+\varepsilon_{2}\right)$ except that the slope of the function becomes a random variable that is realized prior to the determination of $\mathrm{p}_{2}$. What we find is that this complication adds computational complexity to the recourse problem, but it does not affect the analytical properties stated in Theorem 2:

THEOREM 3. Let $D\left(p_{2}, \varepsilon_{2}, \beta_{2}\right)=a_{2}-\beta_{2} p_{2}+\varepsilon_{2}$ denote the demand function for market 2 , where $\varepsilon_{2}$ and $\beta_{2}$ are random variables and $\beta_{2}$ is independent of $\varepsilon_{1}$. Suppose that $\beta_{2}$ is realized prior to setting the market 2 decision policy and that $\varepsilon_{2}$ is realized after setting the policy. Then:

(a) Given $z_{1}, E\left[\Pi\left(Q, z_{1}\right)\right]$ is non-decreasing and concave in $Q$.

(b) Given $\mathrm{Q}$, if $\partial \mathrm{F}_{2}\left(\mathrm{x} \mid \mathrm{t}=\mathrm{z}_{1}\right) / \partial \mathrm{z}_{1} \leq 0$, then $E\left[\Pi\left(\mathrm{Q}, \mathrm{z}_{1}\right)\right]$ is non-decreasing in $\mathrm{z}_{1}$.

\section{Summary and General Applicability of the Recourse Analysis}

In Section 3, we demonstrated a solution procedure to assure that the recourse problem can be solved optimally after information obtained from market 1 is used to generate the distribution used to characterize the uncertainty in market 2 demand. The analysis resulted in a solution that could take any one of five forms depending on the realized capacity level of the second-choice supplier. Then, because the expected optimal recourse profit cannot be determined until information is made available at the conclusion of the first selling season, we established analytical properties of the expected optimal 
recourse profit in expectation of the information that might be obtained. Finally, by formulating a model in which a foreign exchange rate can be absorbed into a price-dependent demand function, we demonstrated the applicability of the recourse model as an extension to the global newsvendor problem.

Although the primary purpose of Section 3 is to provide a building block for analyzing and understanding the two-period problem with learning introduced in Section 2, we find that it has more general applicability. In particular, Section 3 provides a formulation, solution, and interpretation of a three-supplier generalization of a newsvendor problem with pricing. The three suppliers are such that the first-choice supplier has a predetermined capacity constraint that is fixed, the second-choice supplier has a pre-determined capacity constraint that is generated randomly, and the last-choice supplier has unlimited capacity. This three-supplier construct, however, can be reinterpreted as a single-supplier construct in which the cost function of purchasing from the supplier is piecewise linear and convex in the amount of units procured. This is a useful reinterpretation because the stocking-quantity solution for a newsvendor who faces such a purchasing-cost function, but does not have the liberty of setting a selling price, is known to be a finite, generalized base-stock policy, which is a policy that is characterized by a sequence of order-up to levels (one for each segment of the piecewise linear cost function) and by the property that the optimal stocking quantity is an increasing function of the initial inventory level (Porteus, 1990). Theorem 1 expands this result: For a newsvendor who does have the liberty of setting a selling price, the characteristics of a finite, generalized base-stock policy apply not only to the optimal stocking quantity, but also to the optimal stocking factor, which incorporates the affects of pricing. Thus, another contribution of the recourse model is the generalization of the results of a newsvendor model in which the purchasing cost is piecewise linear and convex to include the case in which demand is price-dependent and pricing is a decision variable.

\section{RELATING $\varepsilon_{1}$ AND $\varepsilon_{2}$ AND THE TRANSFER OF INFORMATION BETWEEN MARKETS}

From Lemma 4, the tractability of the solution procedure analyzed in Section 3 to determine the optimal recourse policy is based on the assumption that $F_{2}(x \mid t)$, which cannot be constructed until $t$ is obtained, is such that $\partial \mathrm{g}_{2}(\mathrm{x} \mid \mathrm{t}) / \partial \mathrm{x}+2 \mathrm{~g}_{2}(\mathrm{x} \mid \mathrm{t})^{2}>0$, where $\mathrm{g}_{2}(\mathrm{x} \mid \mathrm{t}) \equiv \mathrm{f}_{2}(\mathrm{x} \mid \mathrm{t}) /\left[1-\mathrm{F}_{2}(\mathrm{x} \mid \mathrm{t})\right]$. In addition, from Theorem 2 , 
the result that $E\left[\Pi\left(Q, z_{1}\right)\right]$ is non-decreasing in $z_{1}$ is based on the assumption that $\partial F_{2}\left(x \mid t=z_{1}\right) / \partial z_{1} \leq 0$. For the purpose of completing the recourse analysis, we assumed that these properties exist. However, these are hardly superfluous assumptions since the form of $F_{2}(x \mid t)$ can differ depending on whether $t$ represents full information or censored information. Therefore, to test the validity of these assumptions, we introduce a specific framework in this section to link markets 1 and 2. Applying the framework, then, we identify conditions to assure $F_{2}(. \mid t)$ will inherit the desired properties.

Suppose that $\varepsilon_{1}$ and $\varepsilon_{2}$ are related in some fashion, but either the relationship between $\varepsilon_{1}$ and $\varepsilon_{2}$ is an uncertain one, or inherent noise exists in one or both of the two market demand structures. In other words, suppose that the scenario is such that some degree of uncertainty will always be present in market 2 , regardless of what is observed in market 1 . As a result, even if the realized value of $\varepsilon_{1}$ can be observed, it cannot be used to resolve all uncertainty embedded in $\varepsilon_{2}$; it could be used only to recharacterize $\varepsilon_{2}$. And, to complicate the informational dynamics further, there is no guarantee that the realized value of $\varepsilon_{1}$ will be observed in the first place: if no leftovers occur in market 1 , then only a lower bound for the realized value of $\varepsilon_{1}$ will be observed.

To operationalize this construct, let $\varepsilon_{1}$ and $\varepsilon_{2}$ be drawings from the same distribution, but suppose that distribution includes an unknown parameter, $\theta$. Then the distribution from which $\varepsilon_{1}$ and $\varepsilon_{2}$ are drawn, say $\Phi(\mathrm{x} \mid \theta)$, is a conditional one that depends on a given value for $\theta$. Since $\theta$ is unknown, we assign $h_{0}(\theta)$, a subjective density function, to characterize $\theta$ prior to the start of the first selling season. As a result, $F_{1}(x)=\int_{0}^{\infty} \Phi(x \mid \theta) h_{0}(\theta) d \theta$. Then, given $t, h_{0}(\theta)$ can be updated to $h_{1}(\theta \mid t)$ using Bayes' formula and $\mathrm{F}_{2}(\mathrm{x} \mid \mathrm{t})$ can be constructed accordingly.

A technical difficulty of this approach is that, in general, the specific form of $h_{1}(\theta \mid t)$ and consequently, the specific form of $F_{2}(x \mid t)$, depends on the type of information obtained from the first selling season. In particular, it depends on whether $t=x_{1}$ (full information) or $t=z_{1}$ (censored information). Thus, a weakness of the Bayesian approach is that it might hinder tractability: in general, the conditions specified in Lemma 4(b) and Theorem 2(b) must be satisfied for two different functional forms. 
However, this weakness can be overcome if $\Phi(\mathrm{x} \mid \theta)$ belongs to the family of "newsboy distributions" (Braden and Freimer, 1991). A newsboy distribution is defined as follows: $\Phi(x \mid \theta)=1-\mathrm{e}^{-\theta n(x)}$, where $\mathrm{n}(\mathrm{x})$ is increasing in $\mathrm{x}$. When a newsboy distribution is paired with an $h_{0}(\theta)$ that is a member of the exponential family of densities, $F_{2}(x \mid t)$ shares the same structural form with $F_{1}(x)$, regardless of whether $h_{1}(\theta \mid t)$ is updated from a t that represents full or censored information. For example, Braden and Freimer demonstrate that if $\Phi(x \mid \theta)=1-e^{-\theta x^{\lambda}}$ (a Weibull distribution) and if $h_{0}(\theta)=\left[\beta^{\alpha} / \Gamma(\alpha)\right] \theta^{\alpha-1} e^{-\beta \theta}$ (a gamma density function), then:

$$
\begin{aligned}
& 1-F_{1}(x)=\left(\frac{\beta}{\beta+x^{\lambda}}\right)^{\alpha} \\
& 1-F_{2}\left(x \mid t=x_{1}\right)=\left(\frac{\beta+x_{1}^{\lambda}}{\beta+x_{1}^{\lambda}+x^{\lambda}}\right)^{\alpha+1}
\end{aligned}
$$

and

$$
1-F_{2}\left(x \mid t=z_{1}\right)=\left(\frac{\beta+z_{1}{ }^{\lambda}}{\beta+z_{1}{ }^{\lambda}+x^{\lambda}}\right)^{\alpha}
$$

Notice that $F_{2}\left(x \mid t=x_{1}\right)$ has the same form as $F_{1}(x)$; the only difference is that $F_{2}\left(x \mid t=x_{1}\right)$ includes $\alpha+$ 1 in place of $\alpha$ and $\beta+x_{1}{ }^{\lambda}$ in place of $\beta$. Similarly, $F_{2}\left(x \mid t=z_{1}\right)$ is equivalent to $F_{1}(x)$ except that $\beta+$ $z_{1}^{\lambda}$ replaces $\beta$.

This example suggests that, with suitable restrictions on the parameters of the newsboy-gamma pair, $\mathrm{F}_{2}(\mathrm{x} \mid \mathrm{t})$ can be assured to inherit the properties required for the validity of Lemma $4(\mathrm{~b})$ and Theorem 2(b). Theorem 4 specifies such restrictions.

THEOREM 4. If $\Phi(x \mid \theta)=1-e^{-\theta n(x)}$ and $h_{0}(\theta)=\left[\beta^{\alpha} / \Gamma(\alpha)\right] \theta^{\alpha-1} e^{-\beta \theta}$, then $d^{2} n^{\prime}(x) / d x^{2} \geq 0$ and $\alpha>1 / 2$ together imply that $\partial \mathrm{g}_{2}(\mathrm{x} \mid \mathrm{t}) / \partial \mathrm{z}+2 \mathrm{~g}_{2}(\mathrm{x} \mid \mathrm{t})^{2}>0$ and $\partial \mathrm{F}_{2}\left(\mathrm{x} \mid \mathrm{t}=\mathrm{z}_{1}\right) / \partial \mathrm{z}_{1} \leq 0$.

Thus, to assure that the conditions in Lemma 4(b) and Theorem 2(b) will be satisfied after $t$ is obtained from market 1 , it suffices to have $h_{0}(\theta)$ be a gamma density with $\alpha \geq 1 / 2$ and $\Phi(x \mid \theta)$ be a newsboy distribution with a convex $n(x)$. Note that the Weibull distribution has $n(x)=x^{\lambda}$, which is convex for $\lambda$ 
$\geq 1$. Note also that the sufficiency conditions stated in Theorem 4 are the same conditions that would be applicable if the market 2 decision problem were an independent, single-period problem with a distribution function for $\varepsilon_{2}$ that was of the form (14). Finally, it is important to note that even with the restrictions stated in Theorem 4, the newsboy-gamma pair provides a great deal of flexibility for approximating a wide range of empirical sales data.

\section{Analysis of the First-Period Problem}

Given the results of Sections 3 and 4, we now are ready to analyze (1), the first-period decision problem, which is to determine $\left(\mathrm{p}_{1}{ }^{*}, \mathrm{~S}_{1} *, \mathrm{Q}^{*}\right)$, the first-period decisions, given that information obtained from market 1 will be transferred to market 2 and that an optimal policy then will be followed in market 2 .

We begin the analysis by making the observation that although both $p_{1}$ and $S_{1}$ influence the optimal expected recourse profit, they do so in a prescribed way. In particular, the links between $\left(\mathrm{p}_{1}, \mathrm{~S}_{1}\right)$ and the recourse decisions can be captured completely through $\mathrm{z}_{1}=\mathrm{S}_{1}+\mathrm{b}_{1} \mathrm{p}_{1}-\mathrm{a}_{1}$, the market 1 stocking factor. We exploit this observation by recasting the first-period decision problem in terms of $z_{1}, p_{1}$, and $Q$ so that $\mathrm{p}_{1}$ can be solved myopically (alternatively, we could recast the problem in terms of $z_{1}, S_{1}$, and $Q$; and then solve for $S_{1}$ myopically). To demonstrate, we define $\Lambda_{1}\left(z_{1}\right)=\int_{0}^{z_{1}} F_{1}\left(x_{1}\right) d x_{1}$ as the expected number of leftovers in market 1 . Then, we substitute for $S_{1}=a_{1}-b_{1} p_{1}+z_{1}$ in (1) and re-write the firstperiod decision problem as follows:

$$
\pi=\max _{\mathrm{p}_{1}, \mathrm{z}_{1}, \mathrm{Q}}\left\{\mathrm{N}_{\mathrm{p}}\left(\mathrm{p}_{1}, \mathrm{z}_{1}\right)+\mathrm{N}_{\mathrm{Q}}\left(\mathrm{Q}, \mathrm{z}_{1}\right)\right\}
$$

where,

$$
N_{p}\left(p_{1}, z_{1}\right)=\left(p_{1}-c_{1}\right)\left(a_{1}-b_{1} p_{1}+z_{1}\right)-\left(p_{1}+h_{1}\right) \Lambda_{1}\left(z_{1}\right)
$$

and

$$
N_{Q}\left(Q, z_{1}\right)=-c_{1} Q+E\left[\Pi\left(Q, z_{1}\right)\right]
$$

Thus, the first-period decision problem is separable in $\mathrm{p}_{1}$ and $\mathrm{Q}$. As a result, if $\mathrm{z}_{1}$ were fixed, then $\mathrm{p}_{1} * \mid \mathrm{z}_{1}$ could be found by maximizing $N_{p}\left(p_{1}, z_{1}\right)$ and $Q^{*} \mid z_{1}$ could be found by maximizing $N_{Q}\left(Q, z_{1}\right)$. This 
observation leads to Lemma 6, which specifies the optimal first-period decisions as unique functions of a pre-determined stocking factor for market 1 . The proof is in the appendix.

LEMMA 6. The optimal first-period decisions can be determined uniquely as functions of $z_{1}$ as follows:
(a) $\quad \mathrm{p}_{1} * \mid \mathrm{z}_{1} \equiv \mathrm{p}_{1}\left(\mathrm{z}_{1}\right)=\frac{\mathrm{a}_{1}+\mathrm{b}_{1} \mathrm{c}_{1}+\mathrm{z}_{1}-\Lambda_{1}\left(\mathrm{z}_{1}\right)}{2 \mathrm{~b}_{1}}$
(b) $\quad \mathrm{S}_{1} * \mid \mathrm{z}_{1} \equiv \mathrm{S}_{1}\left(\mathrm{z}_{1}\right)=\frac{\mathrm{a}_{1}-\mathrm{b}_{1} \mathrm{c}_{1}+\mathrm{z}_{1}+\Lambda_{1}\left(\mathrm{z}_{1}\right)}{2}$
(c) $Q^{*} \mid z_{1} \equiv Q\left(z_{1}\right)$ satisfies: $\begin{cases}\frac{\partial E\left[\Pi\left(Q, z_{1}\right)\right]}{\partial Q}=c_{1} & \text { if }\left.\frac{\partial E\left[\Pi\left(Q, z_{1}\right)\right]}{\partial Q}\right|_{Q=0}>c_{1} \\ Q\left(z_{1}\right)=0 & \text { if }\left.\frac{\partial E\left[\Pi\left(Q, z_{1}\right)\right]}{\partial Q}\right|_{Q=0} \leq c_{1}\end{cases}$

From Lemma 6, if a value of $z_{1}$ is given, then $p_{1}{ }^{*}$ and $S_{1}{ }^{*}$ can be determined explicitly. And, although the determination of $\mathrm{Q}_{1} * \mid z_{1} *$ requires solving an implicit function, efficient computational techniques can be employed because the solution to this implicit function is unique. Moreover, this implicit function has intuitive appeal: For a given $\mathrm{z}_{1}, \mathrm{Q}_{1} *$ is the value of $\mathrm{Q}$ that equates expected marginal revenue $\left(\partial E\left[\Pi\left(Q, z_{1}\right)\right] / \partial Q\right)$ with expected marginal cost $\left(c_{1}\right)$; if expected marginal revenue is strictly less than expected marginal cost for all $Q$, then $Q_{1} * z_{1}=0$.

As a result of Lemma 6 , the problem of determining $\left(\mathrm{p}_{1}{ }^{*}, \mathrm{~S}_{1}{ }^{*}, \mathrm{Q}^{*}\right)$, the optimal decision vector for the first selling period, reduces to an optimization problem over $\mathrm{z}_{1}$ :

$$
\pi=\max _{z_{1}}\left\{N_{p}\left(p_{1}\left(z_{1}\right), z_{1}\right)+N_{Q}\left(Q\left(z_{1}\right), z_{1}\right)\right\}
$$

That is, the two-period decision problem with recourse, which includes as many as seven decisions (including recourse decisions) can be transformed into a single-decision problem. In particular, the problem reduces to a search for $z_{1} *$, the optimal stocking factor for market 1 . Then, given $z_{1}^{*}$, all optimal decisions can be determined: $\left(\mathrm{p}_{1}{ }^{*}, \mathrm{~S}_{1} *, \mathrm{Q}^{*}\right)$, the first-period decisions, can be determined 
immediately from Lemma 6; and $\left(\mathrm{p}_{2}{ }^{*}, \mathrm{q}_{1}{ }^{*}, \mathrm{q}_{12}{ }^{*}, \mathrm{q}_{2}{ }^{*}\right)$ can be determined from Theorem 1 after the first selling period concludes and $t$ is collected.

We have had little success identifying general analytical conditions under which $N_{p}\left(p_{1}\left(z_{1}\right), z_{1}\right)+$ $\mathrm{N}_{\mathrm{Q}}\left(\mathrm{Q}\left(\mathrm{z}_{1}\right), \mathrm{z}_{1}\right)$ is sufficiently well-behaved so as to guarantee that $\mathrm{z}_{1}$ * can be found using simple search algorithms. Nevertheless, since we have reduced the two-period decision problem with recourse to a single-variable model, even a worst-case scenario involving an exhaustive search can be performed fairly painlessly, given the widespread accessibility of capable computing technology. And, under suitable conditions identified below, an accessible lower bound can be determined to reduce the search domain for $\mathrm{z}_{1}{ }^{*}$. This lower bound corresponds to the myopic optimal stocking factor for market 1 .

To demonstrate, first define $z_{s p}$ as the optimal stocking factor for market 1 if the first-selling period were treated as a single-period problem. Then, $\mathrm{z}_{\mathrm{sp}}=\operatorname{argmax}\left\{\mathrm{N}_{\mathrm{p}}\left(\mathrm{p}_{1}\left(\mathrm{z}_{1}\right), \mathrm{z}_{1}\right)\right\}$. From Petruzzi and Dada (1999a), $z_{s p}$ can be found efficiently for the general class of distributions that satisfy $\mathrm{dg}_{1}(\mathrm{x}) / \mathrm{dx}+2 \mathrm{~g}_{\mathrm{I}}(\mathrm{x})^{2}$ $>0$, where $\mathrm{g}_{1}(\mathrm{x})=\mathrm{f}_{1}(\mathrm{x}) /\left[1-\mathrm{F}_{1}(\mathrm{x})\right]$ is the hazard rate function associated with $\varepsilon_{1}$. Theorem 5 establishes that $z_{\mathrm{sp}}$ is a lower bound for $z_{1} *$ if the relationship between market 1 and market 2 is such that Theorem 4 applies. The proof is in the appendix.

THEOREM 5. If $\partial \mathrm{F}_{2}\left(\mathrm{x} \mid \mathrm{t}=\mathrm{z}_{1}\right) / \partial \mathrm{z}_{1} \leq 0$, then $\mathrm{z}_{1} * \geq \mathrm{z}_{\mathrm{sp}}$.

This conclusion is an intuitive one for two reasons. The first reason is a straightforward one: A higher stocking factor corresponds to a higher number of expected leftovers. Since there is a potential second opportunity to sell leftovers when recourse exists, leftovers have less of an "overage" cost associated with them in the two-period scenario than they do in the single-period scenario. The second reason requires more explanation, but briefly stated: A higher stocking factor increases the likelihood of learning about the uncertainty associated with demand. Since there is an opportunity to exploit learned information only when recourse exists, learning is more valuable in the two-period scenario than it is in the single-period scenario. 
To explore more fully the meaning of learning in this context, consider the following comparison to a full-information variant of the two-period decision problem with recourse. (In what follows, we hold $Q$ constant to simplify the comparative analysis.) Suppose that it somehow were possible to observe the realized value of $\varepsilon_{1}$ regardless of whether or not leftovers occur in market 1 . Then, no matter what happens in market $1, t=x_{1}$ and the distribution for $\varepsilon_{2}$ can be constructed from full information. Accordingly, the expected profit associated with market 2 (taken at the beginning of period 1) would be:

$$
E\left[\Pi_{F}\left(Q, z_{1}\right)\right]=\int_{0}^{z_{1}} \Pi_{F}\left(Q, z_{1} \mid t=x_{1}<z_{1}\right) f_{1}\left(x_{1}\right) d x_{1}+\int_{z_{1}}^{\infty} \Pi_{F}\left(Q \mid t=x_{1} \geq z_{1}\right) f_{1}\left(x_{1}\right) d x_{1}
$$

where the subscript " $F$ " identifies this as the full-information case. Note that $\Pi_{F}\left(Q \mid t=x_{1}<z_{1}\right)$ in (21) is equivalent to $\Pi\left(Q, z_{1} \mid t=x_{1}\right)$ in (2). Note also that $\Pi_{F}\left(Q \mid t=x_{1} \geq z_{1}\right)$ in (21) is independent of $z_{1}$. This is because, with full information, the distribution for $\varepsilon_{2}$ is $F_{2}\left(x \mid x_{1}\right)$; and since $x_{1} \geq z_{1}$, there are no leftovers available to transfer to market 2. Next, Theorem 6 establishes that, if Theorem 4 applies, then the optimal first-period stocking factor in the censored-information scenario is no less than the optimal first-period stocking factor in a comparable full-information scenario. The proof is in the appendix.

THEOREM 6. Let $\mathrm{z}_{1 \mathrm{~F}} *$ denote the optimal market 1 stocking factor in the full-information variant. If $\partial \mathrm{F}_{2}\left(\mathrm{x} \mid \mathrm{t}=\mathrm{z}_{1}\right) / \partial \mathrm{z}_{1} \leq 0$, then $\mathrm{z}_{1} * \geq \mathrm{z}_{1 \mathrm{~F}} *$

Thus, whereas Theorem 5 indicates that inventory recourse (the opportunity to stock leftovers for possible sale in a subsequent period) results in a higher stocking factor than when no recourse exists, Theorem 6 indicates that information recourse (the opportunity to obtain information otherwise unavailable when leftovers occur) results in an even higher stocking factor.

This can be explained as follows. When full information is guaranteed regardless of the operating decisions implemented, then information is free in the sense that no proactive measures are required for learning to occur. However, if full information is not guaranteed, then it must be "purchased." The "purchase price" of this information is a higher $z_{1} *$. That is, when information is subject to censoring, a higher $z_{1}$ * represents a short-term cost because a higher $z_{1} *$ corresponds to a higher number of expected leftovers; but, in return, the higher $\mathrm{z}_{1}^{*}$ increases the opportunity to learn in the sense that it increases the 
likelihood that information otherwise unobservable can be obtained (e.g., if $z_{1}$ is increased to $z_{1}$, then learning occurs if $z_{1} \leq x_{1}<z_{1}^{\prime}$, where $x_{1}$ denotes the realized value of $\left.\varepsilon_{1}\right)$. This phenomenon of "paying" for information through an increase in short-term leftovers is related to a similar phenomenon observed by Lariviere and Porteus (1999). They find that, for the case of a perishable product and an exponential underlying demand distribution (that is not price dependent), the optimal stocking quantity in a multi-period planning horizon with censored updating is greater than or equal to the optimal stocking quantity in a single-period horizon.

It is extremely intuitive that information is valuable and hence, "learning" comes at a cost (e.g., higher short-term leftovers). However, by comparing a censored-information scenario to a full-information scenario, we find that the idea of learning in our context is based not so much on what occurs (the revision of a distribution), but rather on how it occurs (through the use of censored information). Moreover, since Lemma 6(a) implies that $\mathrm{dp}_{1} * / \mathrm{dz}_{1} *=\left[1-\mathrm{F}_{1}\left(\mathrm{z}_{1} *\right)\right] / 2 \mathrm{~b}_{1}>0$, which implies that a higher $\mathrm{z}_{1} *$ results in a higher $\mathrm{p}_{1}^{*}$, we also find that a portion of the learning cost is passed on to the consumer when demand uncertainty is additive.

\section{ConClusion}

In this paper we developed a comprehensive approach for analyzing pricing and inventory decisions in a two-period retail setting when an opportunity to refine information about uncertain demand is available. One contribution of the analysis is the solution procedure: we show that all decisions (up to seven in all, including recourse decisions) can be determined uniquely if the first-period stocking factor is known. Hence, as for the most general single-period model considered by Petruzzi and Dada (1999a), the twoperiod decision problem with recourse reduces to a search, albeit a more complex one, for one decision variable. A second contribution of the analysis is the policy implications: we find that the cost of learning is (1) a consequence of censored information because, on the margin, learning is free if full information is guaranteed; (2) measured in the form of a higher stocking factor; and (3) shared with the consumer in the form of a higher selling price when demand uncertainty is additive. A third contribution of the analysis is the application of the results to the motivating examples that highlight the 
natural role of information gathered in one market to enhance decision making in other related markets separated in time or space. In the remainder of this section, we return to these examples to demonstrate the scope of our model.

Our model applies directly to Example 1, thus solving optimally for the stocking and pricing decisions relevant to a prevalent case in market research, namely the case of using a single test market prior to a widespread launch (Lilien et al., 1992). However, market research involving multiple test markets may be more appropriate for retailers who wish to learn about demand, depending on the situation. Based in part on that motivation, Fisher and Rajaram developed a model to exploit (1) historical patterns to select a subset of markets as test markets and (2) test-market-demand information to revise forecasts for the overall selling season. Their analysis introduces some of the difficulties that arise in empirical settings, particularly if censoring is an issue. Lariviere and Porteus (1999) address censoring, but they focus on the important special case of perishable inventory and pre-determined prices. And, Little (1966), to whom the notion of using multiple markets to collect good information to be used over time can be traced, operationalized promotion level instead of selling price as a control variable affecting demand.

As the analyses of Fisher and Rajaram, Lariviere and Porteus, and Little suggest, the implementation of exact mathematical models to market research problems involving multiple test sites can be quite challenging. Our research supports this. Nevertheless, the two-period decision problem with recourse studied in this paper can be extended in principle to supplement such work. This is because the recourse analysis of Section 3 would continue to apply even if multiple test markets were used in period 1 . The only two adjustments to Section 3 would be: (1) the realized capacity constraint of the second-choice supplier would depend on the sum of leftovers remaining from the first period, and (2) the distribution constructed to characterize $\varepsilon_{2}$ would depend on the vector of information collected from the first period. Generally speaking, the construction technique introduced in Section 4 is no more difficult conceptually when $t$ is a vector instead of a scalar. Moreover, it can be shown that the properties of Theorem 2 and 3 continue to hold when $z_{1}$ is a vector instead of a scalar. As a result, the analysis of this paper still could be applied to reduce a two-period, multiple-test-site decision problem with recourse to a search for first- 
period stocking factors, although finding an exact solution to the problem would be substantially more complex computationally because the search would be for an optimal decision vector.

Our model also applies directly to Example 2, thus solving a fairly comprehensive generalization of a global newsvendor problem introduced by Kouvelis and Gutierrez (1997). In particular, our generalization incorporates (1) retail pricing, (2) learning from censored sales information, and (3) an option to pool purchasing resources. We find that a key to applying our model to this example is the transformation of foreign exchange risk into uncertainty surrounding the slope of the price-dependent demand function. This transformation is possible because we follow the lead of Kouvelis and Gutierrez and assume that the exchange rate is realized at the start of the recourse period.

While our model also applies directly to the two-period version of Example 3, we find that a direct extension to longer horizons would be quite challenging. To understand why this is so, consider the role that the stocking factor plays in defining the statistic t. Uncertainty in demand in a given period determines not only how much stock is transferred, but also the nature of the information that is transferred (full vs. censored). These informational dynamics create the stumbling block: although the pricing decision for any given period could be localized once a (recourse) distribution is constructed, the construction of such a distribution would depend on the entire history of t's from earlier periods.

This is in sharp contrast to a related model considered by Petruzzi and Dada (1998b). In that model, demand is not stochastic, although uncertainty exists because a parameter of the price-dependent demand curve is unknown to the decision maker. Once the unknown parameter is revealed, which occurs in a multi-period horizon the first time that leftovers occur, demand becomes deterministic. As a result, the entire history of t's is not required to construct the distribution to characterize a given period's $\varepsilon$. Instead, only the most recent $t$ is sufficient. This result leads to a backward-substitution algorithm that reduces all stocking and pricing decisions over the multi-period horizon to a singlevariable search. However, numerical experience with that model suggests that the effect of future periods on the current decisions diminish rapidly as the planning horizon grows. 
Given this insight, one application for the two-period model analyzed in this paper is as a rollinghorizon approximation to a multiple period setting. This approximation then could be improved with the addition of a suitable reward at the end of the second period to adjust for the impact of remaining periods that are dropped. It would be interesting to determine whether this reward could be chosen such that it provides bounds on the performance of the resulting optimal policy. Another promising avenue for extending the two-period analysis to longer horizons would be to reduce the complexity of the informational dynamics, for example, by finding a mechanism for obtaining full information. One way of obtaining such information would be to use an emergency supplier to fill all unmet demand at the end of each period (as in Eeckhoudt et al., 1995).

\section{APPENDIX: PROOFS}

LEMMA 2. Let $\Lambda_{2}\left(z_{2} \mid t\right) \equiv \int_{0}^{z_{2}} F_{2}\left(x_{2} \mid t\right) d x_{2}$ and suppose that $S_{2}$ were given (which, from Lemma 1, implies given values for $q_{1}, q_{12}$, and $q_{2}$ ). Then, from (5) and (7):

$$
\begin{aligned}
\frac{\partial R\left(p_{2}, q_{1}, q_{12}, q_{2} \mid t\right)}{\partial p_{2}} & =S_{2}-\Lambda_{2}\left(z_{2} \mid t\right)-b_{2}\left(p_{2}+h_{2}\right) F_{2}\left(z_{2} \mid t\right) \\
& =z_{2}+a_{2}-\Lambda_{2}\left(z_{2} \mid t\right)-b_{2} h_{2} F_{2}\left(z_{2} \mid t\right)-b_{2}\left[1+F_{2}\left(z_{2} \mid t\right)\right] p_{2} \\
\frac{\partial^{2} R\left(p_{2}, q_{1}, q_{12}, q_{2} \mid t\right)}{\partial p_{2}{ }^{2}} & =-2 b F_{2}\left(z_{2} \mid t\right)-b^{2}\left(p_{2}+h\right) f_{2}\left(z_{2} \mid t\right)<0
\end{aligned}
$$

So, for a given $S_{2}, R\left(p_{2}, q_{1}, q_{12}, q_{2} \mid t\right)$ is concave in $p_{2}$. Therefore, $p_{2}{ }^{*}$ can be determined as the unique solution to the implicit function $\partial R\left(p_{2}, q_{1}, q_{12}, q_{2} \mid t\right) / \partial p_{2}=0$, if a value of $S_{2}$ is given:

$$
\mathrm{p}_{2} * \mid \mathrm{S}_{2} \equiv \mathrm{p}_{2}\left(\mathrm{z}_{2} \mid \mathrm{t}\right)=\frac{\mathrm{a}_{2}+\mathrm{z}_{2}-\Lambda_{2}\left(\mathrm{z}_{2} \mid \mathrm{t}\right)-\mathrm{b}_{2} \mathrm{~h}_{2} \mathrm{~F}_{2}\left(\mathrm{z}_{2} \mid \mathrm{t}\right)}{\mathrm{b}_{2}\left[1+\mathrm{F}_{2}\left(\mathrm{z}_{2} \mid t\right)\right]}
$$

Notice, $\mathrm{p}_{2}{ }^{*}$ is written solely as a function of $\mathrm{z}_{2}$. Thus, from (7), we can also write:

$$
S_{2} * \mid z_{2} \equiv S_{2}\left(z_{2} \mid t\right)=a_{2}-b_{2} p_{2}\left(z_{2} \mid t\right)+z_{2}=\frac{\Lambda_{2}\left(z_{2} \mid t\right)+\left(a_{2}+b_{2} h_{2}+z_{2}\right) F_{2}\left(z_{2} \mid t\right)}{1+F_{2}\left(z_{2} \mid t\right)}
$$


LEMMA 3. To prove this lemma, it suffices to show that $\partial S_{2}\left(z_{2} \mid t\right) / \partial z_{2}>0$. Thus, from Lemma $2(b)$ :

$$
\begin{aligned}
\frac{\partial S_{2}\left(z_{2} \mid t\right)}{\partial z_{2}} & =\frac{2 F_{2}\left(z_{2} \mid t\right)+\left(a_{2}+b_{2} h_{2}+z_{2}\right) f_{2}\left(z_{2} \mid t\right)}{1+F_{2}\left(z_{2} \mid t\right)}-\frac{\left[\Lambda_{2}\left(z_{2} \mid t\right)+\left(a_{2}+b_{2} h_{2}+z_{2}\right) F_{2}\left(z_{2} \mid t\right)\right] f_{2}\left(z_{2} \mid t\right)}{\left[1+F_{2}\left(z_{2} \mid t\right)\right]^{2}} \\
& =\frac{2 F_{2}\left(z_{2} \mid t\right)\left[1+F_{2}\left(z_{2} \mid t\right)\right]+\left(a_{2}+b_{2} h_{2}+z_{2}-\Lambda_{2}\left(z_{2} \mid t\right)\right) f_{2}\left(z_{2} \mid t\right)}{\left[1+F_{2}\left(z_{2} \mid t\right)\right]^{2}}>0
\end{aligned}
$$

The inequality follows because $z_{2}-\Lambda_{2}\left(z_{2} \mid t\right)=\int_{0}^{z_{2}}\left[1-F_{2}(x \mid t)\right] d x>0$.

LEMMA 4. To prove this lemma, it suffices to show that $M\left(z_{2} \mid t\right)=c_{j}+h_{2}($ for $j=0,12,2)$ has a unique solution and that, at that solution, $M\left(z_{2} \mid t\right)$ is decreasing in $z_{2}$. Thus, from (7) and the proof of Lemma 3:

$$
\begin{aligned}
\frac{\partial \mathrm{p}_{2}\left(\mathrm{z}_{2} \mid \mathrm{t}\right)}{\partial \mathrm{z}_{2}} & =\frac{1}{\mathrm{~b}_{2}}\left(1-\frac{\partial \mathrm{S}_{2}\left(\mathrm{z}_{2} \mid t\right)}{\partial \mathrm{z}_{2}}\right)=\frac{1}{\mathrm{~b}_{2}}\left(1-\frac{2 \mathrm{~F}_{2}\left(\mathrm{z}_{2} \mid \mathrm{t}\right)+\mathrm{b}_{2}\left(\mathrm{p}_{2}\left(\mathrm{z}_{2} \mid \mathrm{t}\right)+\mathrm{h}_{2}\right) \mathrm{f}_{2}\left(\mathrm{z}_{2} \mid \mathrm{t}\right)}{1+\mathrm{F}_{2}\left(\mathrm{z}_{2} \mid \mathrm{t}\right)}\right) \\
& =\frac{1-\mathrm{F}_{2}\left(\mathrm{z}_{2} \mid \mathrm{t}\right)}{\mathrm{b}_{2}\left[1+\mathrm{F}_{2}\left(\mathrm{z}_{2} \mid \mathrm{t}\right)\right]}\left[1-\mathrm{b}_{2}\left(\mathrm{p}_{2}\left(\mathrm{z}_{2} \mid \mathrm{t}\right)+\mathrm{h}_{2}\right) \mathrm{g}_{2}\left(\mathrm{z}_{2} \mid \mathrm{t}\right)\right]
\end{aligned}
$$

where $g_{2}\left(z_{2} \mid t\right) \equiv f_{2}\left(z_{2} \mid t\right) /\left[1-F_{2}\left(z_{2} \mid t\right)\right]$. Therefore:

$$
\begin{aligned}
\frac{\partial M\left(z_{2} \mid t\right)}{\partial z_{2}} & =\left[1-F_{2}\left(z_{2} \mid t\right)\right] \frac{\partial p_{2}\left(z_{2} \mid t\right)}{\partial z_{2}}-\left(p_{2}\left(z_{2} \mid t\right)+h_{2}\right) f_{2}\left(z_{2} \mid t\right) \\
& =\left[1-F_{2}(z \mid t)\right]\left[\frac{1-F_{2}\left(z_{2} \mid t\right)}{b_{2}\left[1+F_{2}\left(z_{2} \mid t\right)\right]}-\left(\frac{2}{1+F_{2}\left(z_{2} \mid t\right)}\right)\left(p_{2}\left(z_{2} \mid t\right)+h_{2}\right) g_{2}\left(z_{2} \mid t\right)\right] \\
& =\frac{1}{b_{2}\left[1+F_{2}\left(z_{2} \mid t\right)\right]}\left[\left(1-F_{2}\left(z_{2} \mid t\right)\right)^{2}-2 b_{2} M\left(z_{2} \mid t\right) g_{2}\left(z_{2} \mid t\right)\right]
\end{aligned}
$$

and hence:

$$
\begin{aligned}
\left.\frac{\partial^{2} M\left(z_{2} \mid t\right)}{\partial z_{2}{ }^{2}}\right|_{\frac{\partial M\left(z_{2} \mid t\right)}{\partial z_{2}}=0} & =\frac{-2}{b_{2}\left[1+F_{2}\left(z_{2} \mid t\right)\right]}\left[\left(1-F_{2}\left(z_{2} \mid t\right)\right) f_{2}\left(z_{2} \mid t\right)+b_{2} M\left(z_{2} \mid t\right) \frac{\partial g_{2}\left(z_{2} \mid t\right)}{\partial z_{2}}\right] \\
& =\frac{-1}{b_{2}\left[1+F_{2}\left(z_{2} \mid t\right)\right]}\left[2\left(1-F_{2}\left(z_{2} \mid t\right)\right)^{2} g_{2}\left(z_{2} \mid t\right)+\frac{\left(1-F_{2}\left(z_{2} \mid t\right)\right)^{2}}{g_{2}\left(z_{2} \mid t\right)} \frac{\partial g_{2}\left(z_{2} \mid t\right)}{\partial z_{2}}\right] \\
& =\frac{-\left[1-F_{2}\left(z_{2} \mid t\right)\right]^{2}}{b_{2}\left[1+F_{2}\left(z_{2} \mid t\right) g_{2}\left(z_{2} \mid t\right)\right.}\left[\frac{\partial g_{2}\left(z_{2} \mid t\right)}{\partial z}+2 g_{2}\left(z_{2} \mid t\right)^{2}\right]<0
\end{aligned}
$$


This inequality implies that $\mathrm{M}\left(\mathrm{z}_{2} \mid \mathrm{t}\right)$ has no local minimum and, at most; one local maximum. In addition, from Lemma $2(a): p_{2}(0 \mid t)=a_{2} / b_{2}$ and $p_{2}(z \rightarrow \infty \mid t)<\infty$. Thus, for $j=0,12$, and $2, M(0 \mid t)=$ $a_{2} / b_{2}+h_{2}>c_{2}+h_{2} \geq c_{j}+h_{2}$ and $M(z \rightarrow \infty \mid t)=0<c_{j}+h_{2}$. Therefore, for $j=0,12$, and $2: M\left(z_{2} \mid t\right)=c_{j}+$ $h_{2}$ has exactly one solution and, at that solution, $M\left(z_{2} \mid t\right)$ is decreasing in $z$.

LEMMA 5. We consider three cases separately.

\section{Case I: Assume $S_{2}\left(z_{2} \mid t\right) \leq Q$}

In this case, from Lemma 1: $q_{1}\left(z_{2} \mid t\right)=S_{2}\left(z_{2} \mid t\right)$ and $q_{12}\left(z_{2} \mid t\right)=q_{2}\left(z_{2} \mid t\right)=0$. Thus, from Lemma 3 , the supply constraint $\mathrm{q}_{1}\left(\mathrm{z}_{2} \mid \mathrm{t}\right) \leq \mathrm{Q}$ implies the constraint $\mathrm{z}_{2} \leq \mathrm{z}_{\mathrm{Q}}$ and therefore, the optimization problem (10) can be written as follows:

$$
\begin{gathered}
\Pi\left(Q, z_{1} \mid t\right)=\max _{z_{2}} R_{1}\left(z_{2} \mid t\right)=\left(p_{2}\left(z_{2} \mid t\right)-c_{0}\right) S_{2}\left(z_{2} \mid t\right)-\left(p_{2}\left(z_{2} \mid t\right)+h_{2}\right) \Lambda_{2}\left(z_{2} \mid t\right) \\
\text { s.t. } z_{2} \leq z_{Q}
\end{gathered}
$$

Consider, from Lemma 2 and the definition of $M\left(z_{2} \mid t\right)$ given in Lemma 4:

$$
\begin{aligned}
\frac{\partial R_{1}\left(z_{2} \mid t\right)}{\partial z_{2}} & =\left(p_{2}\left(z_{2} \mid t\right)-c_{0}\right) \frac{\partial S_{2}\left(z_{2} \mid t\right)}{\partial z_{2}}-\left(p_{2}\left(z_{2} \mid t\right)+h_{2}\right) F_{2}\left(z_{2} \mid t\right)+\left[S_{2}\left(z_{2} \mid t\right)-\Lambda_{2}\left(z_{2} \mid t\right)\right] \frac{\partial p_{2}\left(z_{2} \mid t\right)}{\partial z_{2}} \\
& =\left(p_{2}\left(z_{2} \mid t\right)-c_{0}\right) \frac{\partial S_{2}\left(z_{2} \mid t\right)}{\partial z_{2}}-\left(p_{2}\left(z_{2} \mid t\right)+h_{2}\right) F_{2}\left(z_{2} \mid t\right)\left[1-b_{2} \frac{\partial p_{2}\left(z_{2} \mid t\right)}{\partial z_{2}}\right] \\
& =\left[M\left(z_{2} \mid t\right)-\left(c_{0}+h_{2}\right)\right] \frac{\partial S_{2}\left(z_{2} \mid t\right)}{\partial z_{2}}
\end{aligned}
$$

From the proof of Lemma $3, \partial S_{2}\left(z_{2} \mid t\right) / \partial z_{2}>0$. Therefore, a necessary condition for $z_{2}$ to be an interior maximum of $R_{1}\left(z_{2} \mid t\right)$ is $M\left(z_{2} \mid t\right)=c_{0}+h_{2}$. But, given Lemma 4 , this condition is sufficient because $\mathrm{M}\left(\mathrm{z}_{2} \mid \mathrm{t}\right)=\mathrm{c}_{0}+\mathrm{h}_{2}$ has exactly one solution, and this solution indeed corresponds to the unconstrained maximum of $R_{I}\left(z_{2} \mid t\right)$. Thus, given that $z_{1}$ is the unique solution to $M\left(z_{2} \mid t\right)=c_{0}+h_{2}, \partial R_{I}\left(z_{2} \mid t\right) / \partial z_{2}>0$ if and only if $z_{2}<z_{1}$. This implies that the solution to $(A 1)$ is $\min \left\{z_{1}, z_{Q}\right\}$. 


\section{Case II: Assume $Q<\mathrm{S}_{2}\left(\mathrm{z}_{2} \mid \mathrm{t}\right) \leq \mathrm{Q}+\mathrm{L}_{1}$}

In this case, from Lemma 1: $q_{1}\left(z_{2} \mid t\right)=Q, q_{12}\left(z_{2} \mid t\right)=S_{2}\left(z_{2} \mid t\right)-Q$, and $q_{2}\left(z_{2} \mid t\right)=0$. Thus, from the corollary to Lemma 1 , the supply constraint $\mathrm{q}_{12}\left(\mathrm{z}_{2} \mid t\right) \leq \mathrm{L}_{1}$ implies the constraint $\mathrm{z}_{2} \leq \mathrm{z}_{\mathrm{Q}+\mathrm{L}}$ and therefore, the optimization problem (10) can be written as follows:

$$
\begin{aligned}
& \Pi\left(Q, z_{1} \mid t\right)= \max _{z_{2}} R_{11}\left(z_{2} \mid t\right)=\left(p_{2}\left(z_{2} \mid t\right)-c_{12}\right) S_{2}\left(z_{2} \mid t\right)-\left(p_{2}\left(z_{2} \mid t\right)+h_{2}\right) \Lambda_{2}\left(z_{2} \mid t\right)+\left(c_{12}-c_{0}\right) Q \\
& \text { s.t. } \quad z_{2} \leq z_{Q+L}
\end{aligned}
$$

Given $Q$, the structure of this problem is analogous to the structure of (A1). Thus, by analogy, the solution to this problem is $\min \left\{z_{\Pi}, z_{Q+L}\right\}$, where $z_{I I}$ is the unique solution to $M\left(z_{2} \mid t\right)=c_{12}+h_{2}$.

\section{Case III: Assume $\mathrm{Q}+\mathrm{L}_{1}<\mathrm{S}_{2}\left(\mathrm{z}_{2} \mid \mathrm{t}\right)$}

In this case, Lemma 1: $q_{1}\left(z_{2} \mid t\right)=Q, q_{12}\left(z_{2} \mid t\right)=L_{1}$, and $q_{2}\left(z_{2} \mid t\right)=S_{2}\left(z_{2} \mid t\right)-Q-L_{1}$. Thus, the optimization problem (10) can be written as follows:

$$
\Pi\left(Q, z_{1} \mid t\right)=\max _{z_{2}} R_{I I I}\left(z_{2} \mid t\right)=\left(p_{2}\left(z_{2} \mid t\right)-c_{2}\right) S_{2}\left(z_{2} \mid t\right)-\left(p_{2}\left(z_{2} \mid t\right)+h_{2}\right) \Lambda_{2}\left(z_{2} \mid t\right)+\left(c_{2}-c_{0}\right) Q+\left(c_{2}-c_{12}\right) L_{1}
$$

Given $Q$ and $L_{1}$, this problem also is analogous to (A1), except there is no supply constraint. Therefore, by analogy, the solution to this problem is $z_{m}$, where $z_{m}$ is the unique solution to $M\left(z_{2} \mid t\right)=c_{2}+h_{2}$.

THEOREM 2. PART (a). Given $z_{1}$ and $x_{1}$, the realized value of $\varepsilon_{1}$, there are two cases: $t=x_{1}$ if $x_{1}$ is observable and $t=z_{1}$ if $x_{1}$ is not observable. The details of the proof are analogous for both cases; thus, we provide them only for the case in which $t=x_{1}$.

First notice, from the definition of $z_{Q}$ (Theorem $1,2^{\text {nd }}$ step) and from Lemma 3:

$$
\frac{\partial z_{Q}}{\partial Q}=\left[\left.\frac{\partial s_{2}\left(z_{2} \mid t=x_{1}\right)}{\partial z_{2}}\right|_{z_{2}=z_{Q}}\right]^{-1}>0
$$

Likewise, since $t=x_{1}$ implies that $L_{1}=z_{1}-x_{1}$ :

$$
\frac{\partial z_{Q+z_{1}-x_{1}}}{\partial Q}=\left[\left.\frac{\partial S_{2}\left(z_{2} \mid t=x_{1}\right)}{\partial z_{2}}\right|_{z_{2}=z_{1}-x_{1}}\right]^{-1}>0
$$


Thus, for a given $z_{1}$, as $Q$ increases, both $z_{Q}$ and $z_{Q+z_{1}-x_{I}}$ increase. However, $z_{I}, z_{I I}$, and $z_{I I}$ all are independent of $\mathrm{Q}$. As a result, (12) implies that as $\mathrm{Q}$ increases, $\Pi\left(\mathrm{Q}, \mathrm{z}_{1} \mid \mathrm{t}=\mathrm{x}_{1}\right)$ progresses from $R_{\text {III }}\left(z_{\text {In }} \mid x_{1}\right)$ to $R_{I I}\left(z_{Q+z_{1}-x_{1}} \mid x_{1}\right)$ to $R_{I I}\left(z_{I n} \mid x_{1}\right)$ to $R_{I}\left(z_{Q} \mid x_{1}\right)$ to $R_{I}\left(z_{I} \mid x_{1}\right)$. Therefore, it is a straightforward, though tedious, exercise to show that $\Pi\left(\mathrm{Q}, \mathrm{z}_{1} \mid \mathrm{t}=\mathrm{x}_{1}\right)$ is continuous in $\mathrm{Q}$.

Next, consider, from Lemma 5 and Theorem 1:

$$
\begin{aligned}
& \frac{\partial R_{\mathrm{II}}\left(\mathrm{z}_{\mathrm{III}} \mid \mathrm{x}_{1}\right)}{\partial \mathrm{Q}}=c_{2}-c_{0} \\
& \frac{\partial \mathrm{R}_{\mathrm{II}}\left(\mathrm{z}_{\mathrm{Q}+\mathrm{z}_{1}-\mathrm{x}_{1}} \mid \mathrm{x}_{1}\right)}{\partial \mathrm{Q}}=M\left(\mathrm{z}_{\mathrm{Q}+\mathrm{z}_{1}-\mathrm{x}_{1}} \mid \mathrm{t}=\mathrm{x}_{1}\right)-\left(\mathrm{c}_{0}+\mathrm{h}_{2}\right) \\
& \frac{\partial \mathrm{R}_{\mathrm{II}}\left(\mathrm{z}_{\mathrm{II}} \mid \mathrm{x}_{1}\right)}{\partial \mathrm{Q}}=c_{12}-c_{0} \\
& \frac{\partial \mathrm{R}_{\mathrm{I}}\left(\mathrm{z}_{\mathrm{Q}} \mid \mathrm{x}_{1}\right)}{\partial \mathrm{Q}}=M\left(\mathrm{z}_{\mathrm{Q}} \mid \mathrm{t}=\mathrm{x}_{1}\right)-\left(\mathrm{c}_{0}+\mathrm{h}_{2}\right) \\
& \frac{\partial \mathrm{R}_{\mathrm{I}}\left(\mathrm{z}_{\mathrm{I}} \mid \mathrm{x}_{1}\right)}{\partial \mathrm{Q}}=0
\end{aligned}
$$

As $z_{Q+z_{1}-x_{1}} \rightarrow z_{\text {II }}$ from above, $\partial \mathrm{R}_{\text {II }}\left(z_{\mathrm{Q}+z_{1}-x_{1}} \mid x_{1}\right) / \partial Q \rightarrow M\left(z_{\text {III }} \mid t=x_{1}\right)-\left(c_{0}+h_{2}\right)=c_{2}-c_{0}=\partial R_{m}\left(z_{\text {III }} \mid x_{1}\right) / \partial Q$. This implies that $\partial \Pi\left(Q, z_{1} \mid t=x_{1}\right) / \partial Q$ is continuous at the value of $Q$ that is such that $z_{Q+z_{1}-x_{1}}=z_{I I I}$. Similarly, as $\mathrm{z}_{\mathrm{Q}+\mathrm{z}_{\mathrm{I}}-\mathrm{x}_{1}} \rightarrow \mathrm{z}_{\mathrm{II}}$ from below; $\partial \mathrm{R}_{\mathrm{II}}\left(\mathrm{z}_{\mathrm{Q}+\mathrm{z}_{1}-\mathrm{x}_{1}} \mid \mathrm{x}_{1}\right) / \partial \mathrm{Q} \rightarrow \partial \mathrm{R}_{\mathrm{II}}\left(\mathrm{z}_{\mathrm{II}} \mid \mathrm{x}_{1}\right) / \partial \mathrm{Q}$; as $\mathrm{z}_{\mathrm{Q}} \rightarrow \mathrm{z}_{\mathrm{II}}$ from above, $\partial \mathrm{R}_{\mathrm{I}}\left(\mathrm{z}_{\mathrm{Q}} \mid \mathrm{x}_{1}\right) / \partial \mathrm{Q} \rightarrow \partial \mathrm{R}_{\mathrm{II}}\left(\mathrm{z}_{\mathrm{I}} \mid \mathrm{x}_{\mathrm{I}}\right) / \partial \mathrm{Q}$; and as $\mathrm{z}_{\mathrm{Q}} \rightarrow \mathrm{z}_{\mathrm{I}}$ from below, $\partial \mathrm{R}_{\mathrm{I}}\left(\mathrm{z}_{\mathrm{Q}} \mid \mathrm{x}_{1}\right) / \partial \mathrm{Q} \rightarrow \partial \mathrm{R}_{\mathrm{I}}\left(\mathrm{z}_{\mathrm{I}} \mid \mathrm{x}_{1}\right) / \partial \mathrm{Q}$. Therefore, $\Pi\left(\mathrm{Q}, \mathrm{z}_{1} \mid t=\mathrm{x}_{1}\right)$ is differentiable for all $\mathrm{Q}$.

Note also, from the proof of Lemma 4 , that although $M\left(z_{2} \mid t=x_{1}\right)$ may first increase for small values of $z_{2}$, the equation $M\left(z_{2} \mid t\right)=c_{2}+h_{2}$ has exactly one solution. Consequently, $M\left(z_{2} \mid t=x_{1}\right)$ must begin its descent in $z_{2}$ at a value of $z_{2}$ that is less than $z_{m}$. Moreover, once $M\left(z_{2} \mid t=x_{1}\right)$ begins decreasing in $z_{2}$, it remains decreasing in $z_{2}$, which implies that $M\left(z_{2} \mid t=x_{1}\right)$ is decreasing for all $z_{2} \geq z_{\text {III. }}$.

We now can piece together the shape of $\Pi\left(Q, z_{1} \mid t=x_{1}\right)$. As $Q$ increases from 0 to the critical value at which $z_{Q+z_{1}-x_{1}}=z_{\text {III }}, \Pi\left(Q, z_{1} \mid t=x_{1}\right)$ increases linearly at a rate of $c_{2}-c_{0}$. Then, as $Q$ increases from the critical value at which $z_{\mathrm{Q}+\mathrm{z}_{1}-\mathrm{x}_{1}}=\mathrm{z}_{\mathrm{III}}$ to the critical value at which $\mathrm{z}_{\mathrm{Q}+\mathrm{z}_{1}-\mathrm{x}_{1}}=\mathrm{z}_{\mathrm{II}}$, the rate of change of 
$\Pi\left(Q, z_{1} \mid t=x_{1}\right)$ is $M\left(z_{Q+z_{1}-x_{1}} \mid t=x_{1}\right)-\left(c_{0}+h_{2}\right)$. But since (1) $z_{Q+z_{1}-x_{1}} \geq z_{I I},(2) M\left(z_{2} \mid t=x_{1}\right)$ is decreasing in $z_{2}$ for $z_{2} \geq z_{I I I}$, and (3) $\partial z_{Q+z_{1}-x_{1}} / \partial Q>0$, the rate of change of $\Pi\left(Q, z_{1} \mid t=x_{1}\right)$ decreases from $M\left(z_{I I I} \mid t=\right.$ $\left.x_{1}\right)-\left(c_{0}+h_{2}\right)=c_{2}-c_{0}$ to $M\left(z_{\Pi} \mid t=x_{1}\right)-\left(c_{0}+h_{2}\right)=c_{12}-c_{0}$ as $Q$ increases such that $z_{Q+z_{1}-x_{1}}$ increases from $z_{m}$ to $z_{\Pi}$. In other words, in this region, $\Pi\left(Q, z_{1} \mid t=x_{1}\right)$ continues to increase as a function of $Q$, but at a decreasing rate. Next, for $Q$ that is such that $z_{Q+z_{1}-x_{1}}>z_{\Pi}$, but $z_{Q}<z_{\Pi}, \Pi\left(Q, z_{1} \mid t=x_{1}\right)$ increases linearly at a rate of $c_{12}-c_{0}$ as $Q$ increases. Then, as $Q$ increases from the critical value at which $z_{Q}=z_{I I}$ to the critical value at which $\mathrm{z}_{\mathrm{Q}}=\mathrm{z}_{\mathrm{I}}, \Pi\left(\mathrm{Q}, \mathrm{z}_{1} \mid \mathrm{t}=\mathrm{x}_{1}\right)$ continues to increase, but again it increases at a decreasing rate until the rate equals 0 . From then on, for all $Q$ that is such that $z_{Q}>z_{1}, \Pi\left(Q, z_{1} \mid t=x_{1}\right)$ remains constant. In summary:, $\Pi\left(Q, z_{1} \mid t=x_{1}\right)$ is non-decreasing and concave in $Q$ for the case $t=x_{1}$.

The details are analogous for the case $t=z_{1}$; hence, $\Pi\left(Q, z_{1} \mid t=z_{1}\right)$ also is continuous, differentiable, nondecreasing, and concave in $Q$. Thus, from (2): $E\left[\Pi\left(Q, z_{1}\right)\right]$, the unconditional optimal expected profit of the recourse problem, is a convex combination of functions that are continuous, differentiable, nondecreasing, and concave in $\mathrm{Q}$. Therefore $\mathrm{E}\left[\Pi\left(\mathrm{Q}, \mathrm{z}_{1}\right)\right]$ possesses those same properties.

PART (b). Given $Q$, we again consider two cases: $t=x_{1}$ and $t=z_{1}$. Unlike in PART (a), however, we approach each case differently, applying an algebraic analysis to the case $t=x_{1}$ and a probabilistic analysis to the case $t=z_{1}$.

If $t=x_{1}$, then $L_{1}=z_{1}-x_{1}>0$, but $F_{2}\left(x \mid t=x_{1}\right)$ is independent of $z_{1}$. Thus, from Theorem $1, z_{Q+z_{1}-x_{1}}$ is increasing in $z_{1}$, but $z_{I}, z_{I}, z_{\Pi}$, and $z_{Q}$ all are independent of $z_{1}$. As a result, the form of $\Pi\left(Q, z_{1} \mid t=x_{1}\right)$ depends on the specific value of $Q$ that is given. In particular, from (12):

- If the given value of $Q$ is such that $z_{Q} \geq z_{I}$, then $\Pi\left(Q, z_{1} \mid t=x_{1}\right)=R_{I}\left(z_{I} \mid x_{1}\right)$ for all $z_{1}>x_{1}$; thus, from Lemma $5, \Pi\left(Q, z_{1} \mid t=x_{1}\right)$ is independent of $z_{1}$.

- If the given value of $Q$ is such that $z_{I}>z_{Q}>z_{I I}$, then $\Pi\left(Q, z_{1} \mid t=x_{1}\right)=R_{I}\left(z_{Q} \mid x_{1}\right)$ for all $z_{1}>x_{1}$; thus, from Lemma $5, \Pi\left(Q, z_{1} \mid t=x_{1}\right)$ is independent of $z_{1}$.

- If the given value of $Q$ is such that $z_{\Pi I} \geq z_{Q}>z_{m I I}$, then $\Pi\left(Q, z_{1} \mid t=x_{1}\right)=R_{\Pi}\left(z_{Q+z_{1}} \cdot x_{1} \mid x_{1}\right)$ for values of $z_{1}$ that are greater than $x_{1}$, but less than the critical value of $z_{1}$ at which $z_{Q_{2}+z_{1}-x_{1}}=z_{11}$; and 
$\Pi\left(Q, z_{1} \mid t=x_{1}\right)=R_{\Pi}\left(z_{I} \mid x_{1}\right)$ for values of $z_{1}$ that are greater than or equal to the critical value of $z_{1}$ at which $z_{Q+z_{1}-x_{1}}=z_{I 1}$. Thus, $\Pi\left(Q, z_{1} \mid t=x_{1}\right)$ is continuous. Moreover, from Lemmas 5 and 4 , $\partial R_{\mathrm{II}}\left(z_{\mathrm{Q}+z_{1}-x_{1}} \mid x_{1}\right) / \partial z_{1}=M\left(z_{Q+z_{1}-x_{1}} \mid t=x_{1}\right)-\left(c_{12}+h_{2}\right) \geq 0$; and $R_{\mathrm{J}}\left(z_{n} \mid x_{1}\right)$ is independent of $z_{1}$.

Thus, $\Pi\left(Q, z_{1} \mid t=x_{1}\right)$ also is differentiable and non-decreasing in $z_{1}$.

- If the given value of $Q$ is such that $z_{m} \geq z_{Q}$, then $\Pi\left(Q, z_{1} \mid t=x_{1}\right)=R_{m}\left(z_{m} \mid x_{1}\right)$ for values of $z_{1}$ that are greater than $x_{1}$, but less than or equal to the critical value of $z_{1}$ at which $z_{Q+z_{1}-x_{1}}=z_{m 1 l}$; $\Pi\left(Q, z_{1} \mid t=x_{1}\right)=R_{\Pi}\left(z_{Q+z_{1} \cdot x_{1}} \mid x_{1}\right)$ for values of $z_{1}$ that are greater than the critical value of $z_{1}$ at which $z_{Q+z_{1}-x_{1}}=z_{\text {III }}$, but less than the critical value of $z_{1}$ at which $z_{Q_{2}+z_{1}-x_{1}}=z_{\Pi}$; and $\Pi\left(Q, z_{1} \mid t=\right.$ $\left.x_{1}\right)=R_{\mathrm{II}}\left(\mathrm{z}_{\mathrm{II}} \mid \mathrm{x}_{1}\right)$ for values of $\mathrm{z}_{1}$ that are greater than or equal to the critical value of $z_{1}$ at which $z_{Q+z_{1}-x_{1}}=z_{\Pi}$. Thus, $\Pi\left(Q, z_{1} \mid t=x_{1}\right)$ is continuous. Moreover, from Lemmas 5 and 4 , $\partial \mathrm{R}_{\mathrm{II}}\left(\mathrm{z}_{\mathrm{III}} \mid \mathrm{x}_{1}\right) / \partial \mathrm{z}_{1}=\left(\mathrm{c}_{2}-\mathrm{c}_{12}\right) ; \partial \mathrm{R}_{\mathrm{II}}\left(\mathrm{z}_{\mathrm{Q}+\mathrm{z}_{1}-\mathrm{x}_{1}} \mid \mathrm{x}_{1}\right) / \partial \mathrm{z}_{1}=\mathrm{M}\left(\mathrm{z}_{\mathrm{Q}+\mathrm{z}_{1}-\mathrm{x}_{1}} \mid \mathrm{t}=\mathrm{x}_{1}\right)-\left(\mathrm{c}_{12}+\mathrm{h}_{2}\right)$; and $\mathrm{R}_{\mathrm{II}}\left(\mathrm{z}_{\mathrm{II}} \mid \mathrm{x}_{1}\right)$ is independent of $z_{1}$. Thus, $\Pi\left(Q, z_{1} \mid t=x_{1}\right)$ also is differentiable and non-decreasing in $z_{1}$.

In summary: $\Pi\left(Q, z_{1} \mid t=x_{1}\right)$ is non-decreasing in $z_{1}$ for any given $Q$.

If $t=z_{1}$, then $F_{2}\left(x \mid t=z_{1}\right)$ is non-increasing in $z_{1}$ by assumption, but $L_{1}=0$ is independent of $z_{1}$. This implies that the expected recourse profit, conditioned on the event that $t=z_{1}$, depends on $z_{1}$ only through the distribution function used to characterize $\varepsilon_{2}$. Thus, for the purpose of this proof, let $\varepsilon_{2 \mid z_{1}}$ denote the random variable associated with market 2 demand when $F_{2}\left(x \mid t=z_{1}\right)$ is the distribution function used to characterize that random variable. Then, from (5), notice that for any given decision vector $\left(p_{2}, q_{1}, q_{12}, q_{2}\right)$, the expected profit associated with the recourse problem can be written as $R\left(p_{2}, q_{1}, q_{12}, q_{2} \mid t=z_{1}\right)=E\left[\Psi\left(\varepsilon_{2 \mid z_{1}}\right)\right]$, where $\Psi\left(\varepsilon_{2 \mid z_{1}}\right) \equiv p_{2}\left(q_{1}+q_{12}+q_{2}\right)-\left(p_{2}+h_{2}\right) \max \left\{\left(z_{2}-\varepsilon_{2 \mid z_{1}}\right), 0\right\}-$ $\left(c_{0} q_{1}+c_{12} q_{12}+c_{2} q_{2}\right)$. Notice that $\Psi\left(\varepsilon_{2 \mid z_{1}}\right)$ is a non-decreasing function of $\varepsilon_{2 \mid z_{1}}$.

Now, consider two arbitrary values of $z_{1}$, say $z_{1 A}$ and $z_{1 B}$. Without loss of generality, let $z_{1 B}>z_{1 A}$. Since $\partial F\left(x \mid t=z_{1}\right) / \partial z_{1} \leq 0, F\left(x \mid t=z_{1 B}\right) \leq F\left(x \mid t=z_{1 A}\right)$. Thus, by definition, $z_{1 B}$ is larger than $z_{1 A}$ in the usual stochastic ordering, which implies that $\mathrm{E}\left[\Psi\left(\varepsilon_{2 k_{1 B}}\right)\right] \geq \mathrm{E}\left[\Psi\left(\varepsilon_{2 \mathrm{z}_{1 \mathrm{~A}}}\right)\right]$ (Buzacott and Shanthikumar, 1993). Therefore, if we define $v=\left(p_{2}, q_{1}, q_{12}, q_{2}\right)$ as any decision vector for the recourse problem, then $\mathrm{R}\left(\mathrm{v} \mid \mathrm{z}_{1 \mathrm{~B}}\right)=\mathrm{E}\left[\Psi\left(\varepsilon_{2 \mid z_{1 \mathrm{~B}}}\right)\right] \geq \mathrm{E}\left[\Psi\left(\varepsilon_{2 \mid z_{1 \mathrm{~A}}}\right)\right]=\mathrm{R}\left(\mathrm{v} \mid \mathrm{z}_{\mathrm{IA}}\right)$. In addition, if we define $\mathrm{v}_{\mathrm{j}}{ }^{*}$ as the optimal decision 
vector for the recourse problem when $\varepsilon_{2 \mathrm{z}_{\mathrm{ij}}}$ is the random variable associated with market 2 demand $(\mathrm{j}=$ $A, B)$, then, by the definition of $v_{B} *, \Pi\left(Q, z_{1 B} \mid t=z_{1 B}\right) \equiv R\left(v_{B} * \mid z_{1 B}\right) \geq R\left(v_{A} * \mid z_{1 B}\right)$. Therefore, $\Pi\left(Q, z_{B B} \mid t=\right.$ $\left.z_{1 B}\right) \equiv R\left(v_{B} * \mid z_{1 B}\right) \geq R\left(v_{A} * \mid z_{1 B}\right) \geq R\left(v_{A} * z_{1 A}\right) \equiv \Pi\left(Q, z_{1 A} \mid t=z_{1 A}\right)$. In summary: if $\partial F\left(x \mid t=z_{1}\right) / \partial z_{1} \leq 0$, then $\Pi\left(Q, z_{1} \mid t=z_{1}\right)$ is non-decreasing in $z_{1}$ for any given $Q$.

Since, for a given $\mathrm{Q}$, both $\Pi\left(\mathrm{Q}, \mathrm{z}_{1} \mid \mathrm{t}=\mathrm{x}_{1}\right)$ and $\Pi\left(\mathrm{Q}, \mathrm{z}_{1} \mid \mathrm{t}=\mathrm{z}_{1}\right)$ are non-decreasing in $\mathrm{z}_{1},(2)$ implies:

$$
\frac{\partial E\left[\Pi\left(Q, z_{1}\right)\right]}{\partial z_{1}}=\int_{0}^{z_{1}} \frac{\partial \Pi\left(Q, z_{1} \mid t=x_{1}\right)}{\partial z_{1}} f_{1}\left(x_{1}\right) d x_{1}+\frac{\partial \Pi\left(Q, z_{1} \mid t=z_{1}\right)}{\partial z_{1}}\left[1-F_{1}\left(z_{1}\right)\right] \geq 0
$$

THEOREM 3. First condition on the event $\beta_{2}=b_{2}$ and solve the conditional recourse problem as per Theorem 1. As a consequence, if $\beta_{2}=b_{2}$ and $t=\min \left\{z_{1}, x_{1}\right\}$, where $x_{1}$ denotes the realized value of $\varepsilon_{1}$ (whether observable or not), then a conditional expected optimal profit can be computed as a function of $Q$ and $z_{1}: \Pi\left(Q, z_{1} \mid t=\min \left\{x_{1}, z_{1}\right\} ; \beta_{2}=b_{2}\right)$. Notice, $\Pi\left(Q, z_{1} \mid t=\min \left\{x_{1}, z_{1}\right\} ; \beta_{2}=b_{2}\right)$ is exactly the same as $\Pi\left(Q, z_{1} \mid t\right)$ from Section 3. Since $\beta_{2}$ and $\varepsilon_{1}$ are independent, we can un-condition on $t$ by integrating over $x_{1}$ and thereby compute $E\left[\Pi\left(Q, z_{1} \mid \beta_{2}=b_{2}\right)\right]$, which is exactly the same as $E\left[\Pi\left(Q, z_{1}\right)\right]$ from Section 3. Theorem 2 therefore implies that $E\left[\Pi\left(Q, z_{1} \mid \beta_{2}=b_{2}\right)\right]$ is non-decreasing and concave in $Q$ for a given $z_{1}$, and non-decreasing in $z_{1}$ for a given $Q$ (assuming that $\left.\partial F_{2}\left(x \mid t=z_{1}\right) / \partial z_{1} \leq 0\right)$. Next, we can integrate over $b_{2}$ and thereby compute $E\left[\Pi\left(Q, z_{1}\right)\right]$, the unconditional expected profit. And, since $E\left[\Pi\left(Q, z_{1}\right)\right]$ is a convex combination of functions that are (1) non-decreasing and concave in $\mathrm{Q}$ for a given $\mathrm{z}_{1}$, and (2) non-decreasing in $z_{1}$ for a given $Q$, the results of the theorem follow.

THEOREM 4. If $\Phi(\mathrm{x} \mid \theta)=1-\mathrm{e}^{-\theta \mathrm{B}(\mathrm{x})}$ and $h_{0}(\theta)=\left[\beta^{\alpha} / \Gamma(\alpha)\right] \theta^{\alpha-1} e^{-\beta \theta}$, then $F_{1}(\mathrm{x})=1-[\beta /(\beta+\mathrm{n}(\mathrm{x}))]^{\alpha}$ and:

$$
\begin{aligned}
& h_{1}\left(\theta \mid t=x_{1}\right)=\frac{\phi\left(x_{1} \mid \theta\right) h_{0}(\theta)}{f_{1}\left(x_{1}\right)}=\frac{\left[\beta+n\left(x_{1}\right)\right]^{\alpha+1}}{\Gamma(\alpha+1)} \theta^{\alpha} e^{-\theta\left[\beta+n\left(x_{1}\right)\right]} \\
& h_{1}\left(\theta \mid t=z_{1}\right)=\frac{\left[1-\Phi\left(z_{1} \mid \theta\right) h_{0}(\theta)\right.}{1-F_{1}\left(z_{1}\right)}=\frac{\left[\beta+n\left(z_{1}\right)\right]^{\alpha}}{\Gamma(\alpha)} \theta^{\alpha-1} e^{-\theta\left[\beta+n\left(z_{1}\right)\right]}
\end{aligned}
$$

Thus: 


$$
1-F_{2}(x \mid t)=\int_{0}^{\infty}[1-\Phi(x \mid \theta)]_{1}(\theta \mid t)= \begin{cases}\left(\frac{\beta+n\left(x_{1}\right)}{\beta+n\left(x_{1}\right)+n(x)}\right)^{\alpha+1} & \text { if } t=x_{1} \\ \left(\frac{\beta+n\left(z_{1}\right)}{\beta+n\left(z_{1}\right)+n(x)}\right)^{\alpha} & \text { if } t=z_{1}\end{cases}
$$

This implies:

$$
g_{2}(x \mid t) \equiv \frac{f_{2}(x \mid t)}{1-F_{2}(x \mid t)}= \begin{cases}\frac{(\alpha+1) n^{\prime}(x)}{\beta+n\left(x_{1}\right)+n(x)} & \text { if } t=x_{1} \\ \frac{\alpha n^{\prime}(x)}{\beta+n\left(z_{1}\right)+n(x)} & \text { if } t=z_{1}\end{cases}
$$

Therefore, given that $\alpha \geq 1 / 2$ and that $\mathrm{n}^{\prime \prime}(\mathrm{x}) \equiv \mathrm{d}^{2} \mathrm{n}(\mathrm{x}) / \mathrm{dx}^{2} \geq 0$ :

$$
\begin{aligned}
& \frac{\partial g_{2}\left(x \mid t=x_{1}\right)}{\partial x}+2 g_{2}\left(x \mid t=x_{1}\right)^{2}=\frac{(\alpha+1) n^{\prime \prime}(x)}{\beta+n\left(x_{1}\right)+n(x)}+\left(\frac{2 \alpha+1}{\alpha+1}\right) g_{2}\left(x \mid t=x_{1}\right)^{2}>0 \\
& \frac{\partial g_{2}\left(x \mid t=z_{1}\right)}{\partial x}+2 g_{2}\left(x \mid t=z_{1}\right)^{2}=\frac{\alpha n^{\prime \prime}(x)}{\beta+n\left(z_{1}\right)+n(x)}+\left(\frac{2 \alpha-1}{\alpha+1}\right) g_{2}\left(x \mid t=z_{1}\right)^{2}>0
\end{aligned}
$$

and:

$$
\frac{\partial\left[1-F_{2}\left(x \mid t=z_{1}\right)\right]}{\partial z_{1}}=\alpha\left(\frac{\beta+n\left(z_{1}\right)}{\beta+n\left(z_{1}\right)+x}\right)^{\alpha-1}\left[\frac{n^{\prime}\left(z_{1}\right) n(\dot{x})}{\left(\beta+n\left(z_{1}\right)+n(x)\right)^{2}}\right]>0
$$

LeMMA 6. PARTS (a) and (b). Given (18), $\mathrm{N}_{\mathrm{p}}\left(\mathrm{p}_{1}, \mathrm{z}_{1}\right)$ is the expected profit function of a single-period newsvendor problem with pricing. From Petruzzi and Dada (1999a), then, $N_{p}\left(p_{1}, z_{1}\right)$ is concave in $p_{1}$; thus, $\mathrm{p}_{1} * \mid \mathrm{z}_{1}$ can be determined as the unique solution to $\partial \mathrm{N}_{\mathrm{p}}\left(\mathrm{p}_{1}, \mathrm{z}_{1}\right) / \partial \mathrm{p}_{1}=0$ :

$$
\mathrm{p}_{1} * \mid \mathrm{z}_{1} \equiv \mathrm{p}_{1}\left(\mathrm{z}_{1}\right)=\frac{\mathrm{a}_{1}+\mathrm{b}_{1} \mathrm{c}_{1}+\mathrm{z}_{1}-\Lambda_{1}\left(\mathrm{z}_{1}\right)}{2 \mathrm{~b}_{1}}
$$

Accordingly, $S_{1} * z_{1}$ can be determined by $S_{1}\left(z_{1}\right)=a-b_{1} p_{1}\left(z_{1}\right)+z_{1}$.

PART (c). From Theorem 2(a), E[ח(Q, $\left.\left.z_{1}\right)\right]$ is concave in $Q$ for a given $z_{1}$. Thus, from (19), $N_{Q}\left(Q, z_{1}\right)$ is concave in $\mathrm{Q}$. Moreover, from the proof of Theorem 2, for arbitrarily large values of $\mathrm{Q}, \partial \mathrm{E}\left[\Pi\left(\mathrm{Q}, \mathrm{z}_{1}\right)\right] / \partial \mathrm{Q}$ $=0$, which implies that $\partial N_{Q}\left(Q, z_{1}\right) / \partial Q=-c<0$. Therefore, given $z_{1}$, either $Q^{*} \mid z_{1}=0$ (boundary-point maximum) or $\mathrm{Q} * \mid z_{1}$ satisfies $\partial \mathrm{N}_{\mathrm{Q}}\left(\mathrm{Q}, \mathrm{z}_{1}\right) / \partial \mathrm{Q}=0$ (interior-point maximum). 
THEOREM 5. Assume that $\partial \mathrm{F}_{2}\left(\mathrm{x} \mid \mathrm{z}_{1}\right) / \partial \mathrm{z}_{1} \leq 0$. From (19):

$$
\frac{d N_{Q}\left(Q\left(z_{1}\right), z_{1}\right)}{d z_{1}}=\frac{\partial N_{Q}\left(Q\left(z_{1}\right), z_{1}\right)}{\partial z_{1}}+\frac{\partial N_{Q}\left(Q\left(z_{1}\right), z_{1}\right)}{\partial Q\left(z_{1}\right)} \frac{d Q\left(z_{1}\right)}{d z_{1}}=\frac{\partial N_{Q}\left(Q\left(z_{1}\right), z_{1}\right)}{\partial z_{1}} \geq 0 .
$$

In (A2), $\left[\partial \mathrm{N}_{\mathrm{Q}}\left(\mathrm{Q}\left(\mathrm{z}_{1}\right), \mathrm{z}_{1}\right) / \partial \mathrm{Q}\left(\mathrm{z}_{1}\right)\right]\left[\mathrm{dQ}\left(\mathrm{z}_{1}\right) / \mathrm{d} \mathrm{z}_{1}\right]=0$ by complementary slackness: if $\mathrm{Q}\left(\mathrm{z}_{1}\right)$ is an interiorpoint maximum of $\mathrm{N}_{\mathrm{Q}}\left(\mathrm{Q}, \mathrm{z}_{1}\right)$; then $\left[\partial \mathrm{N}_{\mathrm{Q}}\left(\mathrm{Q}\left(\mathrm{z}_{1}\right), \mathrm{z}_{1}\right) / \partial \mathrm{Q}\left(\mathrm{z}_{1}\right)\right]=0$ by definition; if $\mathrm{Q}\left(\mathrm{z}_{1}\right)$ is a boundary-point solution, then $\mathrm{dQ}\left(\mathrm{z}_{1}\right) / \mathrm{dz_{1 }}=0$. And, $\partial \mathrm{N}_{\mathrm{Q}}\left(\mathrm{Q}\left(\mathrm{z}_{1}\right), \mathrm{z}_{1}\right) / \partial \mathrm{z}_{1}=\partial \mathrm{E}\left[\Pi\left(\mathrm{Q}\left(\mathrm{z}_{1}\right), \mathrm{z}_{1}\right)\right] / \partial \mathrm{z}_{1} \geq 0$ because $\partial \mathrm{F}_{2}\left(\mathrm{x} \mid \mathrm{z}_{1}\right) / \partial \mathrm{z}_{1} \leq$ 0 implies, by Theorem $2(b)$, that $\partial E\left[\Pi\left(Q\left(z_{1}\right), z_{1}\right)\right] / \partial z_{1} \geq 0$.

Therefore, we have: (a) $z_{\text {sp }}$ is the value of $z_{1}$ that maximizes $N_{p}\left(p_{1}\left(z_{1}\right), z_{1}\right)$, by the definition of $z_{s p}$; (b) $z_{1} *$ is the value of $z_{1}$ that maximizes $N_{p}\left(p_{1}\left(z_{1}\right), z_{1}\right)+N_{Q}\left(Q_{1}\left(z_{1}\right), z_{1}\right)$, by the definition of $z_{1} *$; and (c) $N_{Q}\left(Q\left(z_{1}\right), z_{1}\right)$ is non-decreasing in $z_{1}$, by (A2). These three points imply that $z_{1} * \geq z_{\text {sp. }}$.

THEOREM 6. Assume that $\partial F_{2}\left(x \mid z_{1}\right) / \partial z_{1} \leq 0$. From (21):

$$
\frac{\partial E\left[\Pi_{F}\left(Q, z_{1}\right)\right]}{\partial z_{1}}=\int_{0}^{z_{1}} \frac{\partial \Pi\left(Q, z_{1} \mid t=x_{1}\right)}{\partial z_{1}} f_{1}\left(x_{1}\right) d x_{1}
$$

But, from (2):

$$
\int_{0}^{z_{1}} \frac{\partial \Pi\left(Q, z_{1} \mid t=x_{1}\right)}{\partial z_{1}} f_{1}\left(x_{1}\right) d x_{1}=\frac{\partial E\left[\Pi\left(Q, z_{1}\right)\right]}{\partial z_{1}}-\frac{\partial \Pi\left(Q, z_{1} \mid t=z_{1}\right)}{\partial z_{1}}\left[1-F_{1}\left(z_{1}\right)\right] \leq \frac{\partial E\left[\Pi\left(Q, z_{1}\right)\right]}{\partial z_{1}}
$$

The inequality follows because $\partial \Pi\left(Q, z_{1} \mid t=z_{1}\right) / \partial z_{1} \geq 0$, from the proof of Theorem $2(b)$. Thus:

$$
\frac{\partial E\left[\Pi\left(Q, z_{1}\right)\right]}{\partial z_{1}} \geq \frac{\partial E\left[\Pi_{F}\left(Q, z_{1}\right)\right]}{\partial z_{1}}
$$

which implies that $z_{1} * \geq z_{1 F} *$, where $z_{1 F} *$ denotes the optimal market 1 stocking factor in the fullinformation variant.

\section{ACKNOWLEDGEMENT}

We graciously acknowledge the editors and two anonymous referees for their helpful comments and suggestions. 


\section{REFERENCES}

AgRAWAL N and S. A. SMITH. 1996. "Estimating Negative Binomial Demand for Retail Inventory Management with Unobservable Lost Sales." Naval Res. Logistics. 43:6, 839-861.

ALPERN, S. and D. J. SNOWER. 1988. "A Search Model of Optimal Pricing and Production." Engineering Costs and Production Economics. 15, 279-284.

Balvers, R. J. and T. F. Cosimano. 1990. "Actively Learning About Demand and the Dynamics of Price Adjustment." The Economic Journal. 100:402, 882-898.

BARLOW, R. E. and F. Proschan. 1965. Mathematical Theory of Reliability. John Wiley \& Sons, New York, NY, 9-45.

BASSOK, Y. and R. ANUPINDI. 1997. "Analysis of Supply Contracts with Total Minimum Commitment." IIE Trans. 29:5, 373-381.

BRADEN, D. J. and M. FREIMER. 1991. "Informational Dynamics of Censored Observations." Management Sci. 37:11, 1390-1404.

and S. S. OREN. 1994. "Nonlinear Pricing to Produce Information." Marketing Sci. 13:3, 310-326.

BuZACotT, J. A. and J. G. ShanTHIKUMAR. 1993. Stochastic Models of Manufacturing Systems. Prentice Hall, Englewood Cliffs, NJ, 543-544.

COCA-COLA COMPANY. 2000 (May 17). "Coca-Cola and Marconi Team in Global Launch of Intelligent Online Vending: Technology Ushers in New Era of Vending Service for the Consumer." Coca-Cola Company Press Release, Atlanta, GA.

EeCKHOUdT, L., C. GollieR, and H. SCHLESINGER. 1995. "The Risk-Averse (and Prudent) Newsboy." Management Sci. 41:5, 786-794.

EMMONS, H. and S. M. GILBERT. 1998. "Note: The Role of Returns Policies in Pricing and Inventory Decisions for Catalogue Goods." Management Sci. 44:2, 276-283.

EPPEN, G. D. and A. V. IYER. 1997. "Backup Agreements in Fashion Buying - The Value of Upstream Flexibility." Management Sci. 43:11,1469-1484.

ERNST, R. L. 1970. "A Linear Inventory Model of a Monopolistic Firm.” Ph.D. Dissertation, University of California, Berkeley, CA.

FISHER, M. L. and A. RAMAN. 1996. "Reducing the Cost of Demand Uncertainty through Accurate Response to Early Sales." Oper. Res. 44:1, 87-99.

and K. RAJARAM. 1999 (revised). "Accurate Retail Testing of Fashion Merchandise: Methodology and Application." Working paper, The Wharton School, University of Pennsylvania.

FRTO-LAY, INC. 1997 (February 21). "WOW! ${ }^{\text {TM }}$ Snacks Hit Store Shelves in Central Indiana on Monday, February 24: Frito-Lay Expands Test Market of Salty Snack Line Made with Olean Fat Replacer." Frito-Lay, Inc. Press Release, Plano, TX.

Grossman, S. J., R. E. Kinlstrom, and L. J. Mrrman. 1977. "A Bayesian Approach to the Production of Information and Learning by Doing." Review of Economic Studies. 44:3, 533-547. 
HARPAZ, G., W. Y. LEE, and R. L. WINKLER. 1982. "Learning, Experimentation, and the Optimal Output Decisions of a Competitive Firm." Management Sci. 28:6, 589-603.

HAYS, C. L. 1999 (October 28). "Variable-Price Coke Machines Being Tested." The NY Times. p. C1.

IYER, A. V. and M. E. BERGEN. 1997. "Quick Response in Manufacturer-Retailer Channels." Management Sci. 43:4, 559-570.

Kouvelis, P. and G. J. Gutierrez. 1997. "The Newsvendor Problem in a Global Market: Optimal Centralized and Decentralized Control Policies For A Two-Market Stochastic Inventory System." Management Sci. 43:5, 571-585.

KROUSE, C. G. and A. J. SENCHACK, JR. 1977. "Probing For Information As A Behavior Of The Firm Under Demand Uncertainty." J. of Economics and Business. 29:3, 163-170.

LARIVIERE, M. A. and E. L. PORTEUS. 1999. "Stalking Information: Bayesian Inventory Management with Unobserved Lost Sales." Management Sci. 45:3, 346-363

LAZEAR, E. P. 1986. "Retail Pricing and Clearance Sales." American Economic Review. 76:1, 14-32.

LILIEN, G. L., P. KOTLER, and K. S. MoORTHY. 1992. Marketing Models. Prentice Hall, Englewood Cliffs, NJ.

LitTLE, J. D. C. 1966. "A Model of Adaptive Control of Promotional Spending." Oper. Res. 14:6, 1075-1097.

NAHMiAS, S. 1994. "Demand Estimation In Lost Sales Inventory Systems." Naval Res. Logistics. 41:6, 739-757.

PetruzZI, N. C. and M. DaDA. 1999a. "Pricing and the Newsvendor Problem: A Review with Extensions." Oper. Res. 47:2, 183-194. and M. DADA. 1999b. "Dynamic Pricing and Inventory Control with Learning." Working Paper. College of Commerce and Business Administration, University of Illinois at Urbana-Champaign.

PORTEUS, E. L. 1990. "Stochastic Inventory Theory," in Heyman, D. P., and M. J. Sobel (Eds.), Handbooks in OR \& MS, Vol. 2, Elsevier, North-Holland, 605-652.

THowsEN, G. T. 1975. "A Dynamic, Nonstationary Inventory Problem For A Price/Quantity Setting Firm." Naval Research Logistics Quarterly. 22:3, 461-476.

TREFLER, D. 1993. "The Ignorant Monopolist: Optimal Learning with Endogenous Information." Internat. Economic Review. 34:3, 565-581.

TSAY, A. A. and W. S. LOVEJOY. 1999. "Quantity Flexibility Contracts and Supply Chain Performance." Manufacturing \& Service Oper. Management. 1:2, 89-111.

ZABEL, E. 1972. "Multiperiod Monopoly Under Uncertainty." J. of Economic Theory. 5:3, 524-536. 